Bulletin of the Seismological Society of America. Vol. 63, No. 5, pp. 1663-1687. October 1973

\title{
REGIONAL VARIATIONS IN THE STRUCTURE OF THE CRUST IN THE CENTRAL UNITED STATES FROM $P$-WAVE SPECTRA
}

\author{
By Tuneto Kurita*
}

\begin{abstract}
Regional variations in the crustal structure in the central United States have been inferred by the transfer ratio method from an analysis of long-period $P$ waves recorded at SHA, OXF, FLO and MDS, the stations nearly along $89^{\circ} \mathrm{W}$ longitude. The crustal structure in this region is approximated by a stack of horizontal parallel layers except possibly in the area around FLO, where the structure is rather complicated. The crustal thickness is predominantly controlled by the thick silicic upper crust, whereas the mafic lower crust is about $10 \mathrm{~km}$ thick throughout this region. The $P$-wave velocity of the lower crust is about 6.9 to $7.0 \mathrm{~km} / \mathrm{sec}$ except probably in the area around FLO, where $7.4 \mathrm{~km} / \mathrm{sec}$ velocity is more likely. A sedimentary layer with a velocity of about $3.0 \mathrm{~km} / \mathrm{sec}$, having a thickness of about $3 \mathrm{~km}$ near the coast of the Gulf of Mexico, tapers out to the north within the Gulf Coastal Plain. Deep discontinuities in the crust may be replaced by transitional layers up to $10 \mathrm{~km}$ thick. The Moho is about $33 \mathrm{~km}$ deep near the coast of the Gulf of Mexico, deepens to about $\mathbf{4 1} \mathrm{km}$ near an intersection of the Gulf coastal plain and the interior plain, reaches about $47 \mathrm{~km}$ or more in the midst of the interior plain, and rises to about $41 \mathrm{~km}$ toward an intersection of the interior plain and the superior upland. As for the midst of the interior plain, however, the depth of the Moho reduces by as much as $5 \mathbf{~ k m}$, if the velocity in the lower crust is about $7.0 \mathrm{~km} /$ sec instead of about $7.4 \mathrm{~km} / \mathrm{sec}$. In any case, the general trend of the depth of the Moho may match with the topographic feature from the Gulf of Mexico to Lake Superior.
\end{abstract}

\section{INTRODUCTION}

The crustal structure in the central United States is studied from an analysis of longperiod $P$ waves. This region is selected for the detailed study, because of the likelihood that the layering is simple there. This study corresponds to the first step of a two-step procedure formulated in Kurita (1973a). The formulation was a development of the transfer ratio method of Phinney (1964), which was based on the Thomson-Haskell matrix method.

\section{DATA}

Data are selected from all available film chips of the WWSSN long-period seismograms of SHA, OXF, FLO, and MDS. In order to study regional variations in crustal structure around these stations, we utilize records of shallow earthquakes which occurred at various azimuths from the station as well as those of deep earthquakes. As apparent from Figure 1 , most of the earthquakes are differentiated into three groups according to the direction of wave approach: northwestern America, northeastern Asia (Alaska, Aleutian, Kurile, Japan); southwestern Asia, southeastern Europe (Turkey, Aegean Sea, Greece); and South America. Therefore, these earthquakes are tabulated separately in Tables 1, 2, and 3. Since the above three groups are almost concerned with the structure under the sector nearly northwest, northeast, and southeast of the station, they will be referred to as the NW, NE, and SE groups or sectors, respectively.

* On leave fram Faculty of Engineering, Kyoto University. 


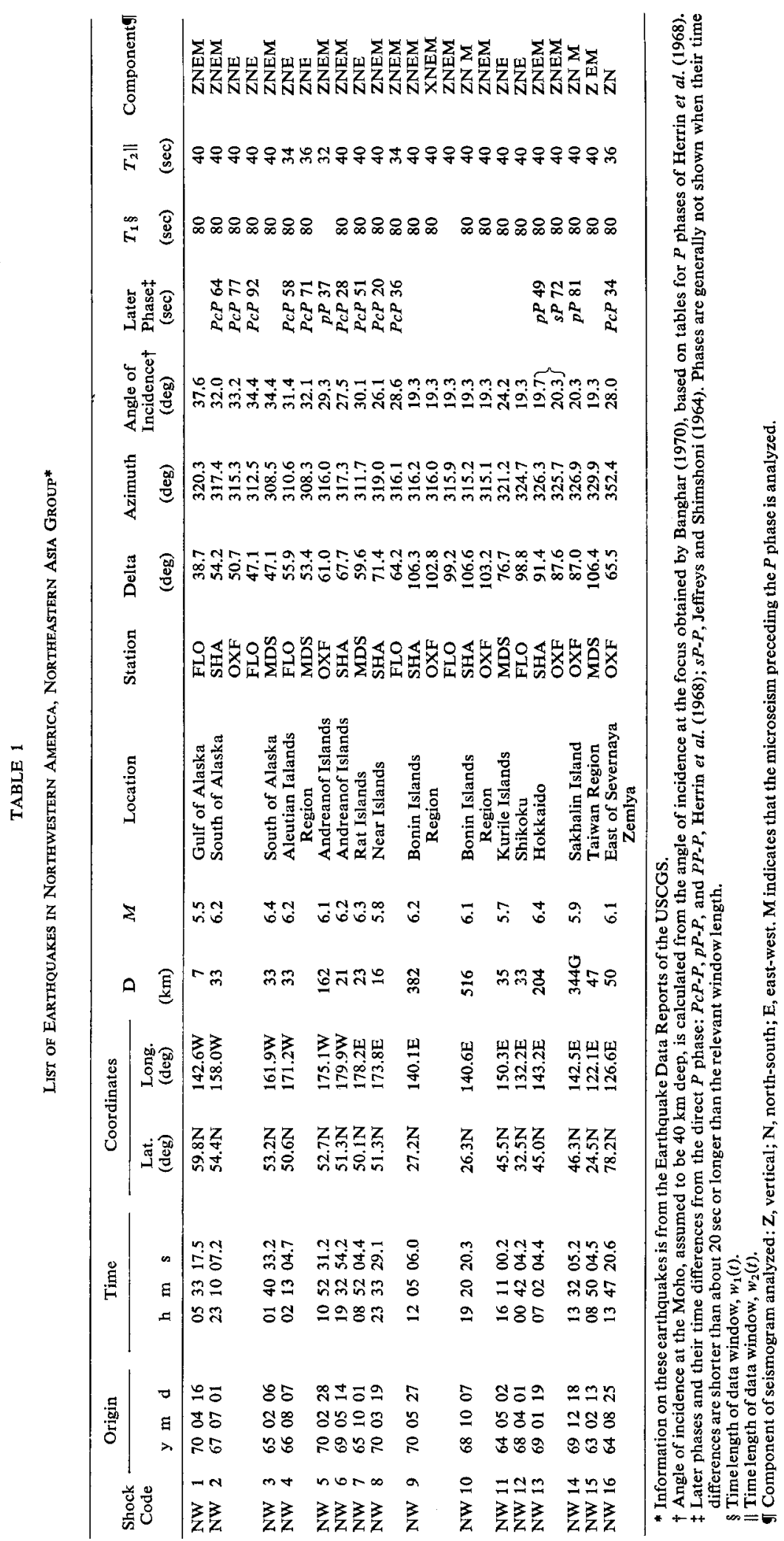




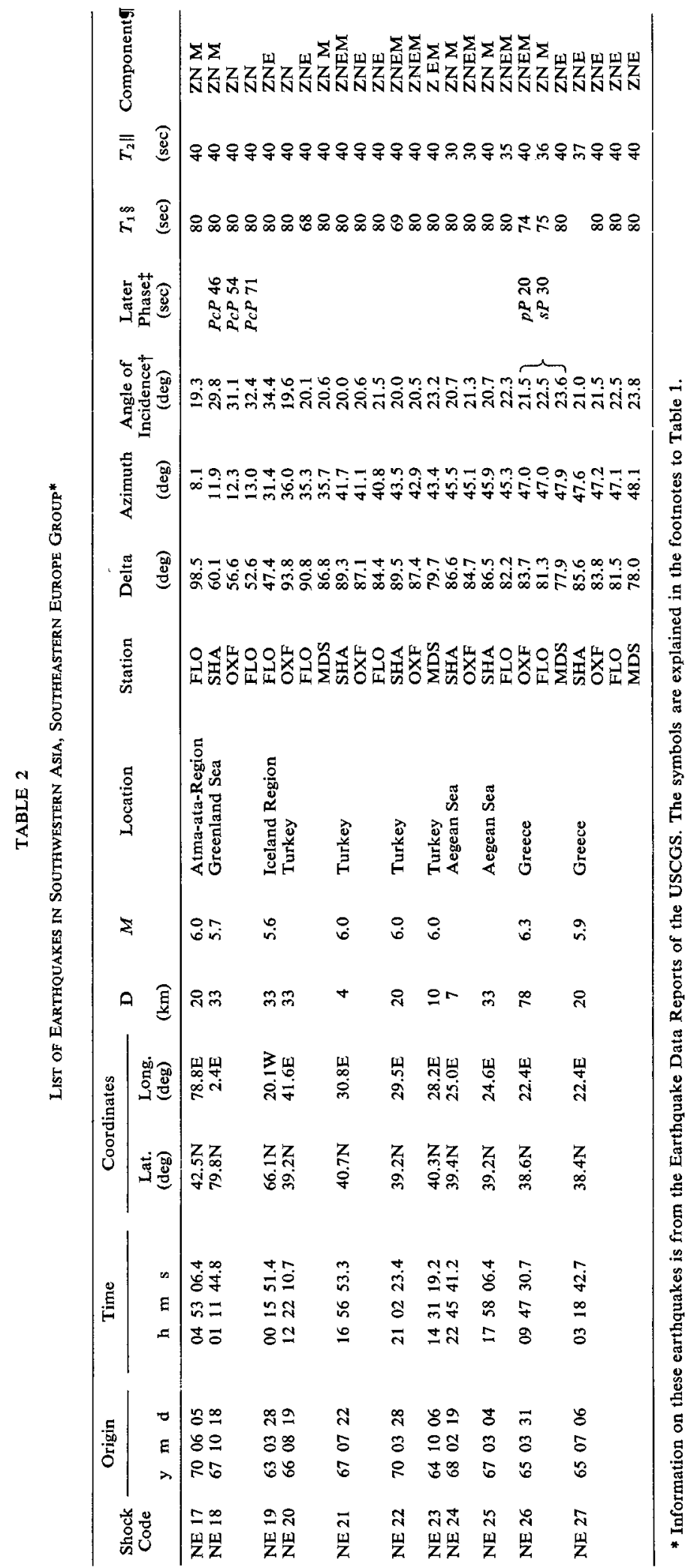




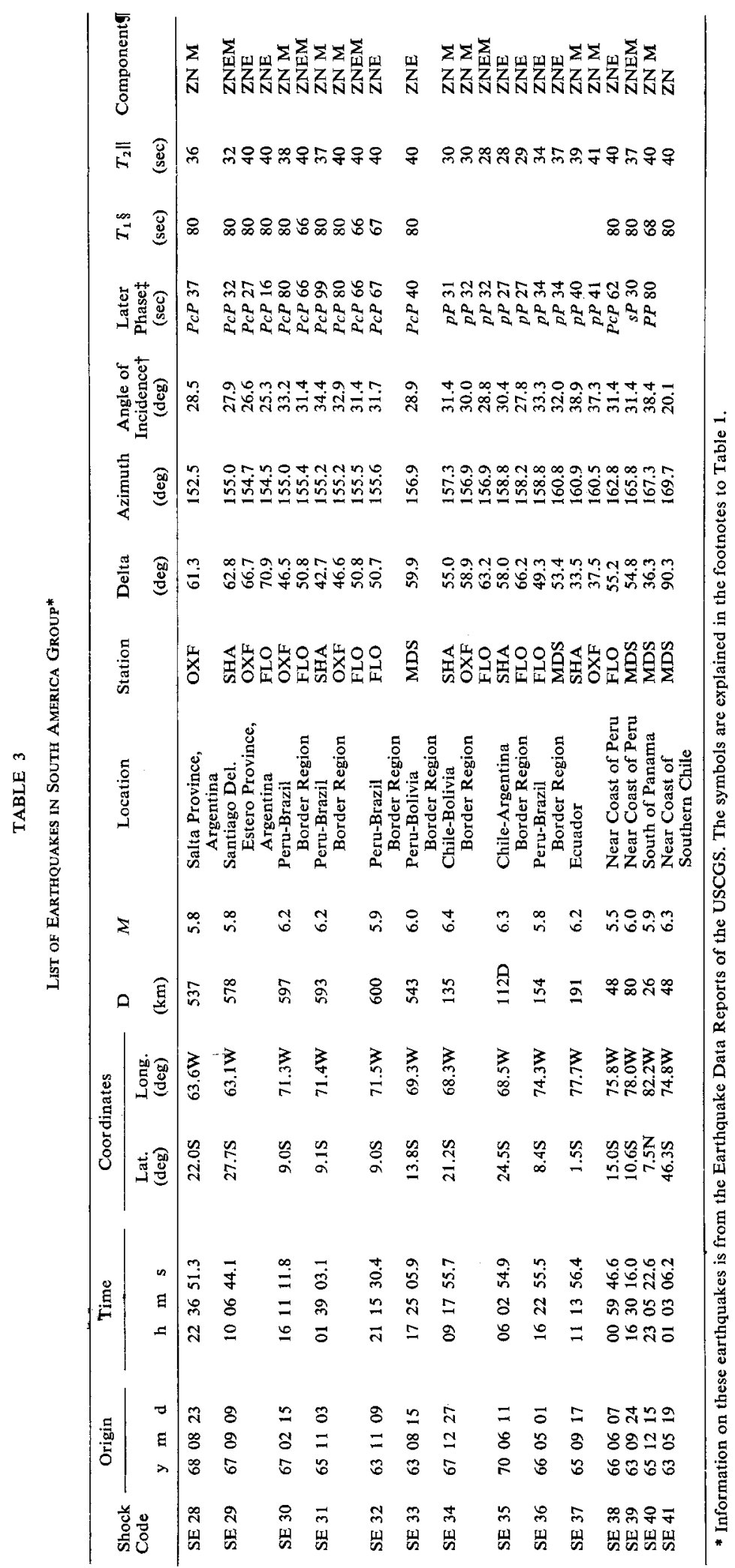




\section{Data Processing for the Study of Crustal Structure}

Assumptions. The following assumptions are made in constructing crustal models.

(a) Crustal model is assumed to be composed of homogeneous parallel layers, each of which has constant velocities and density.

(b) $P$-wave velocity models are assumed, which were derived from nearby refraction surveys.

(c) $S$-wave velocities and densities are assumed to be related to $P$-wave velocities by the relations,

$$
\begin{aligned}
& \beta=[(1-2 \sigma) /(2-2 \sigma)]^{\frac{1}{2} \alpha} \\
& \rho=2.35+0.036(\alpha-3.0)^{2}
\end{aligned}
$$

where Poisson's ratio, $\sigma$, is taken as 0.26 . The latter relation is composed of the experimental relations of Woollard (1959), and Nafe and Drake (1963).

Possible deviations of the actual structure from the above assumptions will be examined later.

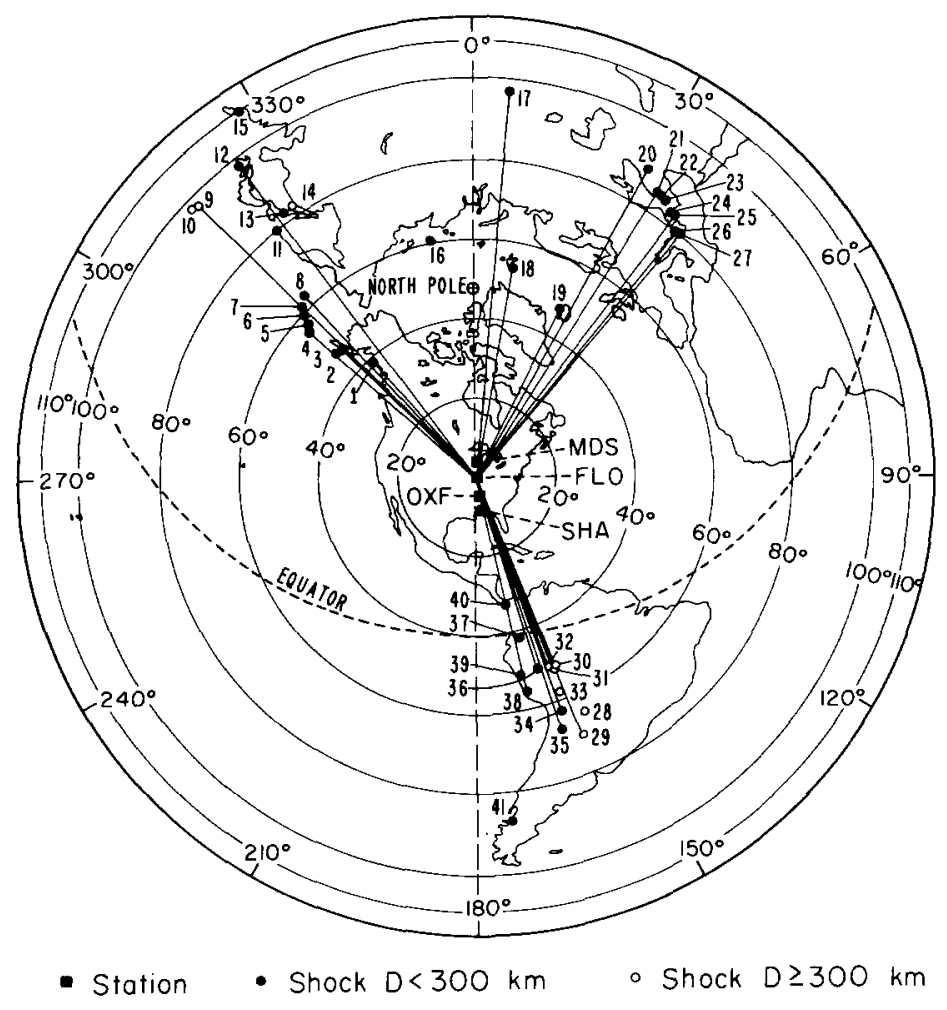

FIG. 1. Geographical distribution of earthquakes relative to four WWSSN stations in the central United States. Solid lines show the propagation paths of body waves to FLO.

Data processing. Previous researches suggest that the crustal thickness in the central United States is about $40 \mathrm{~km}$. For this amount of crustal thickness, a time length of about $40 \mathrm{sec}$ of the teleseismic $P$ phase contains most of the information on the crustal layering (Kurita, 1973a). However, even for records of deep earthquakes, this time length is seldom free from later phases, and for those of shallow earthquakes, this time length contains surface and near-surface reflections around the source, bringing troughs into the resultant spectrum. The insensitivity of the transfer ratio to the angle of incidence to the Moho, 
makes it possible to superpose observational transfer ratios for earthquakes with different focal depths and almost the same directions of wave approach. This manipulation enables one to locate trough positions and to compose further reliable observational ratios.

By taking the fiducial time at the beginning of the direct $P$ phase, we apply one wing of one or both of the data windows, $w_{1}(t)$ and $w_{2}(t)$ to the signal, where

$$
\begin{aligned}
& w_{1}(t)=1 / T_{1} \cdot\left[\sin \left(\pi t / T_{1}\right) /\left(\pi t / T_{1}\right)\right]^{2} \\
& |t|<T_{1} \\
& w_{2}(t)=1 / T_{2} \cdot\left[1-\left(t / T_{2}\right)^{20}\right] \\
& |t|<T_{2}
\end{aligned}
$$

These data windows and an illustration of the signal modification due to their multiplication are shown in Figure 2 with the corresponding spectral windows. $T_{1}$ and $T_{2}$, the time length of the above data windows, are taken as 80 and $40 \mathrm{sec}$, respectively. When no strong later phases are observed within a time length of about $40 \mathrm{sec}, w_{2}(t)$ applied with

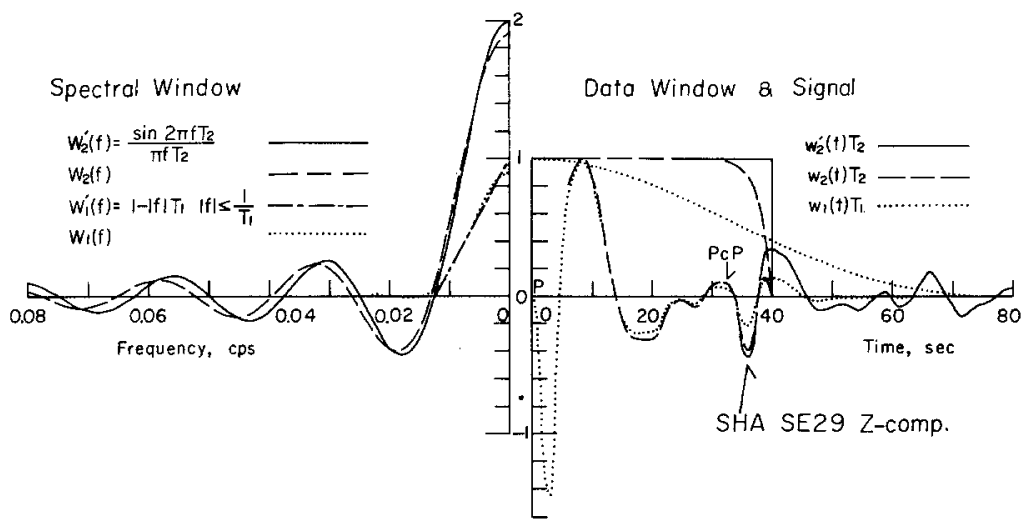

FIG. 2. The right half shows one wing of each of the data windows, $w_{1}(t), w_{2}(t)$, and $w_{2}{ }^{\prime}(t)$ (rectangular window), multiplied by $T_{1}(80 \mathrm{sec})$ or $T_{2}(40 \mathrm{sec})$, and an illustration of the signal modification due to their application. The vertical component of a $\boldsymbol{P}$-wave record of a deep earthquake in South America observed at SHA is shown with a solid line, while the signals multiplied by the data windows are shown with the same lines with the data windows. In the left half is shown one wing of each of the spectral windows corresponding to the above data windows, and $w_{1}^{\prime}(f)$, the Fourier pair of $w_{1}^{\prime}(t)=1 / T_{1}$. [ $\sin \left(\pi t / T_{1}\right) /$ $\left.\left(\pi t / T_{1}\right)\right]^{2},|t|<\infty$.

$T_{2}$ of $40 \mathrm{sec}$ best conserves information on the crustal layering of about $40 \mathrm{~km}$. However, some distortions in the resultant spectrum are unavoidable due to the rather large side lobes of the corresponding spectral window. A vertical $P$-wave record at SHA contains the $P c P$ phase at about $32 \mathrm{sec}$ after the $P$ phase. Since the signal multiplied by $w_{2}(t)$ with $T_{2}$ of $40 \mathrm{sec}$ does not taper the $P c P$ phase and rather distorts the signal, we have taken $T_{2}$ as $32 \mathrm{sec}$ as shown in Table 3. $w_{2}(t)$ is exclusively used when the time length is shortly limited due to a strong later phase. When we can take the time length as long as $80 \mathrm{sec}$, a multiplication of $w_{1}(t)$ may bring about the spectrum with sufficient information on the crustal layering. In Figure 2, it is observed that this window nearly succeeds in tapering out the $P c P$ phase. However, we had better not apply this window with a time length as short as $40 \mathrm{sec}$, because its strong smoothing effect produces a featureless spectrum. Thus, by taking the time length of $80 \mathrm{sec}$ for $w_{1}(t)$ and $40 \mathrm{sec}$ for $w_{2}(t)$ as far as possible, and sometimes varying the time length, we calculate observational transfer ratios and obtain a composite for each earthquake. Resultant composites are put together separately for each group. On the other hand, the theoretical transfer ratio is calculated on the assumptions made above. By varying each layer thickness of the assumed velocity models within a probable range, computing transfer ratios, and comparing them with observational ratios, we obtain one or two "best-fit models" in each group for each assumed velocity 
model. Thereafter, the best-fit models are rated subjectively in accordance with the quality of fit (see Tables 4, 5, 6 and 7). Among these models "the best models" are selected in each group (see Table 8). All through the above procedure, some objective measure is desirable, but difficult at present.

TABLE 4

Crustal Models around Spring Hill (SHA)

\begin{tabular}{|c|c|c|c|c|c|c|c|c|c|}
\hline \multirow{2}{*}{ Model } & \multirow{2}{*}{ Parameter } & \multicolumn{6}{|c|}{ Layer } & \multirow{2}{*}{ Reference } & \multirow{2}{*}{$\begin{array}{l}\text { Quality } \\
\text { of Fit** }\end{array}$} \\
\hline & & 1 & 2 & 3 & 4 & 5 & 6 & & \\
\hline \multirow{3}{*}{$\begin{array}{l}\text { Ansleyt } \\
\text { Warren, Healy, and } \\
\text { Jackson (1966) }\end{array}$} & $a(\mathrm{~km} / \mathrm{sec})$ & 3.0 & 5.1 & 6.0 & & 6.9 & $8.3 \|$ & \multirow[t]{3}{*}{ Fig. 3(d) } & \multirow[t]{3}{*}{$\mathrm{D}(\mathrm{SE})$} \\
\hline & $\rho\left(\mathrm{g} / \mathrm{cm}^{3}\right)$ & 2.3 & 2.6 & 2.8 & & 3.0 & 3.3 & & \\
\hline & $\mathrm{H}(\mathrm{km})$ & 4.0 & 2.0 & 15.0 & & 20.0 & $(41.0)$ & & \\
\hline \multirow[t]{3}{*}{ Raleight } & $a(\mathrm{~km} / \mathrm{sec})$ & 3.0 & 4.8 & 5.9 & & 6.9 & $8.4 \|$ & \multirow[t]{3}{*}{ Fig. 3(d) } & \multirow[t]{3}{*}{$\mathrm{D}(\mathrm{SE})$} \\
\hline & $\rho\left(\mathrm{g} / \mathrm{cm}^{3}\right)$ & 2.3 & 2.6 & 2.8 & & 3.0 & 3.3 & & \\
\hline & $H(\mathrm{~km})$ & 3.0 & 5.0 & 5.0 & & 16.0 & $(29.0)$ & & \\
\hline \multirow{4}{*}{$\begin{array}{l}\text { Dribble } † \\
\quad \text { Springer (1966) }\end{array}$} & $a(\mathrm{~km} / \mathrm{sec})$ & 4.4 & 4.8 & 6.0 & & 6.8 & 8.3 & \multirow[t]{4}{*}{ Fig. 3(d) } & \multirow[t]{4}{*}{$\mathrm{B}(\mathrm{SE})$} \\
\hline & $\beta(\mathrm{km} / \mathrm{sec})$ & 2.5 & 2.7 & 3.6 & & 4.1 & 4.6 & & \\
\hline & $\rho\left(\mathrm{g} / \mathrm{cm}^{3}\right)$ & 2.2 & 2.3 & 2.8 & & 3.0 & 3.4 & & \\
\hline & $\mathrm{H}(\mathrm{km})$ & 3.0 & 2.5 & 11.0 & & 20.0 & (36.5) & & \\
\hline \multirow[t]{2}{*}{ SHA71-NW } & $\alpha(\mathrm{km} / \mathrm{sec}) \ddagger$ & 3.0 & 5.0 & 6.0 & & 6.9 & 8.1 & \multirow[t]{2}{*}{ Fig. 3(a) } & \multirow[t]{2}{*}{$\mathbf{A}$} \\
\hline & $\mathrm{H}(\mathrm{km})$ & 3.0 & $3.0 \S$ & 15.0 & & 11.0 & $(32.0)$ & & \\
\hline NE & $\mathrm{H}(\mathrm{km})$ & 3.0 & $3.0 \S$ & 15.0 & & 12.0 & $(33,0)$ & Fig. 3(b) & $\mathbf{A}$ \\
\hline SE & $\mathrm{H}(\mathrm{km})$ & 3.0 & $3.0 \$$ & 13.0 & & 16.0 & $(35.0)$ & Fig. 3(c) & $\mathbf{A A}$ \\
\hline SE1 & $H(\mathrm{~km}) \ddagger$ & 3.0 & 0.0 & 16.0 & & 16.0 & $(35.0)$ & Fig. 3(d) & $\mathbf{A A}$ \\
\hline SE2 & $H(\mathrm{~km}) \ddagger$ & 0.0 & 3.0 & 16.0 & & 16.0 & $(35.0)$ & Fig. 3(d) & B \\
\hline SE3 & $\mathbf{H}(\mathrm{km}) \ddagger$ & 4.0 & 2.0 & 13.0 & & 16.0 & $(35.0)$ & Fig. $3(d)$ & C \\
\hline \multirow[t]{2}{*}{ SHA71-NW-A } & $\alpha(\mathrm{km} / \mathrm{sec}) \ddagger$ & 3.0 & & \multirow{2}{*}{\multicolumn{3}{|c|}{$\begin{array}{r}6.6 \\
34.0\end{array}$}} & 8.15 & \multirow[t]{2}{*}{ Fig. 3(a) } & \multirow[t]{2}{*}{ B } \\
\hline & $H(\mathrm{~km})$ & $0.0 \S$ & & & & & $(34.0)$ & & \\
\hline NE-A & $H(\mathrm{~km})$ & $0.0 \S$ & & & 35.0 & & $(35.0)$ & Fig. 3(b) & $\mathbf{B}$ \\
\hline SE-A & $\mathrm{H}(\mathrm{km})$ & $0.0 \S$ & & & 37.0 & & $(37.0)$ & Fig. 3(c) & B \\
\hline SE-A1 & $\mathrm{H}(\mathrm{km})$ & 4.0 & & & 33.0 & & $(37.0)$ & Fig. 3(d) & A \\
\hline
\end{tabular}

* Rank of fit of the transfer ratio of the model to the observational transfer ratios concerned: AA, excellent; A, good (satis factory); B, fair; C, poor; D, nonfit. The sector letter in the parentheses shows the sector for which the comparison has been made. When the sector letter is not shown, it means that the rank of fit is the same for three sectors.

$\uparrow$ Proposed model.

* Parameters are assumed.

$\S$ Assumed value.

II $\pm 0.3 \mathrm{~km} / \mathrm{sec}$.

TABLE 5

Crustal Models around Oxford (OXF)

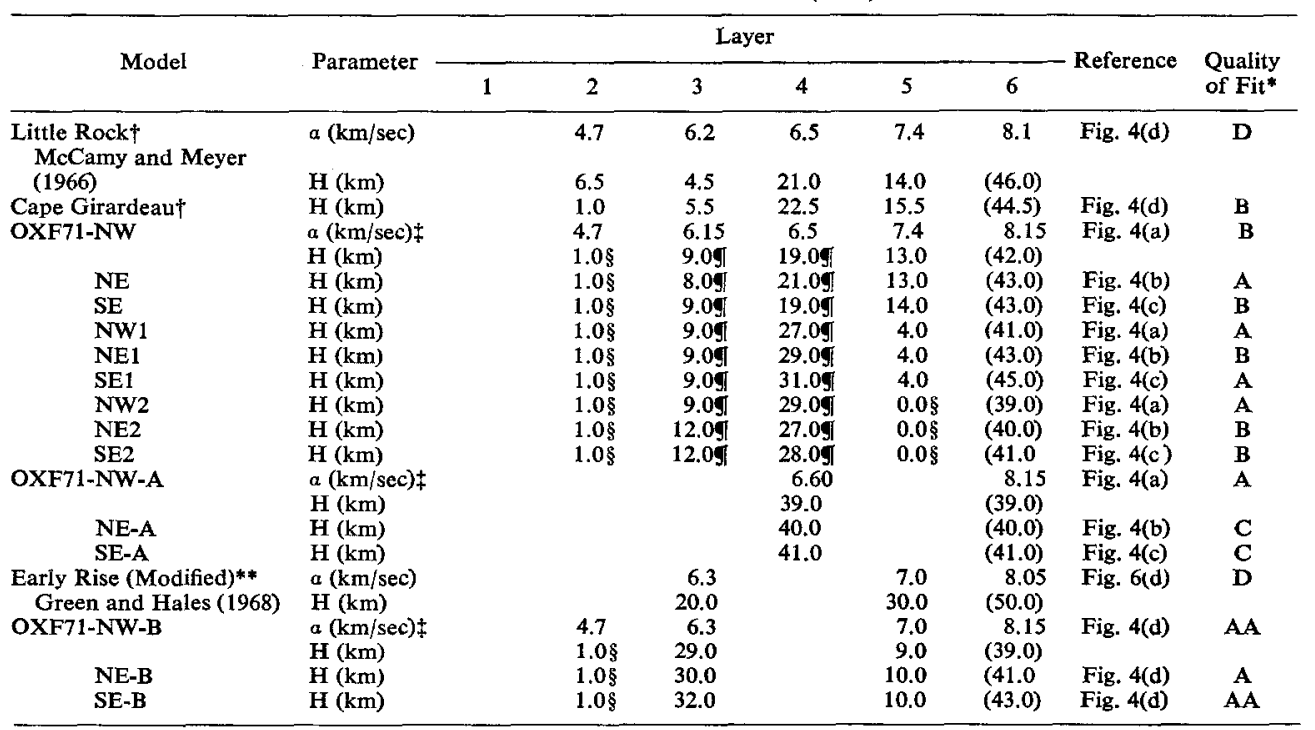

Symbols *, $\uparrow, \ddagger, \S$, are explained in the footnotes to Table 4 .

T The boundary between two layers marked with this symbol in the same row, can be moved by as much as $10 \mathrm{~km}$, with the same or a little worse quality of fit.

** Modified proposed model in which the 6.30 and $7.00 \mathrm{~km} / \mathrm{sec}$ layers are substituted for the transitional layers of the proposed model, which has a linear increase of the velocity one from 6.30 to $6.35 \mathrm{~km} / \mathrm{sec}$ over $20 \mathrm{~km}$, and another from 6.85 to $7.15 \mathrm{~km} / \mathrm{sec}$ over $30 \mathrm{~km}$. 
TABLE 6

Crustal Models Around Florissant (FLO)

\begin{tabular}{|c|c|c|c|c|c|c|c|c|c|}
\hline \multirow{2}{*}{ Model } & \multirow{2}{*}{ Parameter } & \multicolumn{6}{|c|}{ Layer } & \multirow{2}{*}{ - Reference } & \multirow{2}{*}{$\begin{array}{l}\text { Quality } \\
\text { of Fit* }\end{array}$} \\
\hline & & 1 & 2 & 3 & 4 & 5 & 6 & & \\
\hline 5A (Hannibal) $\dagger$ & $a(\mathrm{~km} / \mathrm{sec})$ & 5.0 & 6.05 & 6.2 & 6.6 & & 7.95 & Fig. 5(d) & $\mathrm{A}(\mathrm{NW})$ \\
\hline Stewart (1968) & $\mathrm{H}(\mathrm{km})$ & 1.0 & 4.0 & 13.5 & 20.0 & & (38.5) & & \\
\hline \multirow[t]{2}{*}{540312 (Ste. Genevieve) } & $a(\mathrm{~km} / \mathrm{sec})$ & 5.0 & 6.05 & 6.25 & 6.9 & & 8.0 & Fig. 5(d) & $\mathrm{C}(\mathrm{SE})$ \\
\hline & $\mathrm{H}(\mathrm{km})$ & 0.5 & 3.0 & 21.5 & 19.5 & & $(44.5)$ & & \\
\hline 540302 (Ste. Genevieve) & H (km) & 0.5 & 3.0 & 36.0 & & & (39.5) & Fig. 5(d) & $\mathrm{B}(\mathrm{SE})$ \\
\hline \multirow[t]{2}{*}{ F1071-NW } & $a(\mathrm{~km} / \mathrm{sec}) \ddagger$ & 5.0 & 6.05 & 6.2 & 6.6 & & 8.15 & Fig. $5(a)$ & A \\
\hline & $\mathbf{H}(\mathrm{km})$ & $1.0 \S$ & $3.0 \S$ & 18.0 & 19.0 & & $(41.0)$ & & \\
\hline NE & $H(\mathrm{~km})$ & $1.0 \S$ & $3.0 \S$ & 17.0 & 20.0 & & $(41.0)$ & Fig. 5(b) & $\mathbf{B}$ \\
\hline \multirow[t]{2}{*}{ SE } & $a(\mathrm{~km} / \mathrm{sec}) \ddagger$ & 5.0 & 6.05 & 6.25 & 6.9 & & 8.15 & Fig. 5(c) & $\mathbf{B}$ \\
\hline & $\mathbf{H}(\mathrm{km})$ & $1.0 \S$ & $3.0 \S$ & 17.0 & 21.0 & & $(42,0)$ & & \\
\hline SE1 & $H(\mathrm{~km})$ & $1.0 \S$ & $3.0 \S$ & 37.0 & & & $(41,0)$ & Fig. 5(d) & C \\
\hline Cape Girardeaut & $a(\mathrm{~km} / \mathrm{sec})$ & 4.7 & & 6.2 & 6.5 & 7.4 & 8.1 & Fig. 5(d) & C(SE) \\
\hline $\begin{array}{l}\text { McCamy and Meyer } \\
\text { (1966) }\end{array}$ & $H(\mathrm{~km})$ & 1.0 & & 5.5 & 22.5 & 15.5 & $(44.5)$ & & \\
\hline \multirow[t]{2}{*}{ FLO71-NW-A } & $a(\mathrm{~km} / \mathrm{sec}) \ddagger$ & 5.0 & & 6.15 & 6.5 & 7.4 & 8.15 & Fig. 5(a) & A \\
\hline & $\mathbf{H}(\mathrm{km})$ & $1.0 \S$ & & 9.09 & $27.0 \mathrm{~g}$ & 9.0 & $(46.0)$ & & \\
\hline NE-A & $\mathbf{H}(\mathrm{km})$ & $1.0 \S$ & & 9.09 & $26.0 \mathrm{~g}$ & 11.0 & $(47.0)$ & Fig. 5(b) & A \\
\hline SE-A & $\mathbf{H}(\mathrm{km})$ & $1.0 \S$ & & 9.09 & $26.0 \mathrm{~g}$ & 12.0 & $(48.0)$ & Fig, 5(c) & A \\
\hline SE-A1 & $\mathbf{H}(\mathrm{km})$ & 1.08 & & $9.0 \mathrm{~g}$ & $38.0 \mathrm{~g}$ & 9.0 & $(57.0)$ & Fig. 5(d) & AA \\
\hline \multirow[t]{2}{*}{ NW-B } & $a(\mathrm{~km} / \mathrm{sec})$ & 5.0 & 6.05 & 6.2 & 6.6 & 7.4 & 8.15 & Fig. 5(a) & $\mathbf{A}$ \\
\hline & $\mathbf{H}(\mathrm{km})$ & $1.0 \$$ & $3.0 \S$ & 17.0 & 16.0 & 9.0 & $(46.0)$ & & \\
\hline NE-B & H (km) & $1.0 \S$ & $3.0 \S$ & 16.0 & 16.0 & 10.0 & $(46.0)$ & Fig. 5(b) & A \\
\hline \multirow[t]{2}{*}{ SE-B } & $a(\mathrm{~km} / \mathrm{sec}) \ddagger$ & 5.0 & 6.05 & 6.25 & 6.9 & 7.4 & 8.15 & Fig. 5(c) & $\mathbf{A A}$ \\
\hline & $\mathrm{H}(\mathrm{km})$ & $1.0 \$$ & $3.0 \$$ & 18.0 & 16.0 & 14.0 & $(52.0)$ & & \\
\hline \multirow{4}{*}{$\begin{array}{l}\text { Central U.S.† } \\
\text { McEvilly (1964) }\end{array}$} & $a(\mathrm{~km} / \mathrm{sec})$ & & 6.1 & 6.4 & 6.7 & & 8.15 & Fig. 5(d) & $\mathrm{B}(\mathrm{NW})$ \\
\hline & $\beta(\mathrm{km} / \mathrm{sec})$ & & 3.5 & 3.7 & 3.95 & & 4.75 & & C(NE, SE) \\
\hline & $\rho\left(\mathrm{g} / \mathrm{cm}^{3}\right)$ & & 2.7 & 2.9 & 2.9 & & 3.3 & & \\
\hline & H (km) & & 11.0 & 9.0 & 18.0 & & $(38.0)$ & & \\
\hline \multirow[t]{2}{*}{ Central U.S. (Modified) } & $a(\mathrm{~km} / \mathrm{sec})$ & & 6.1 & 6.4 & 6.7 & & 8.15 & Fig. 5(d) & $\mathrm{C}(\mathrm{SE})$ \\
\hline & $H(\mathrm{~km})$ & & 11.0 & 9.0 & 18.0 & & $(38.0)$ & & \\
\hline FLO (Two Layer) $\dagger$ & $a(\mathrm{~km} / \mathrm{sec})$ & & & 6.2 & 6.6 & & 8.2 & not shown & $\begin{array}{c}A(N W) \\
B(N E, S E)\end{array}$ \\
\hline \multicolumn{10}{|l|}{ Fernandez and Careage } \\
\hline \multirow[t]{3}{*}{ FLO (One Layer) $\dagger$} & $a(\mathrm{~km} / \mathrm{sec})$ & & & & 6.5 & & 8.2 & not shown & $A(N W)$ \\
\hline & & & & & & & & & $(\mathrm{NE}, \mathrm{SE})$ \\
\hline & $\mathbf{H}(\mathbf{k m})$ & & & & 43.0 & & $(43.0)$ & & \\
\hline \multirow[t]{2}{*}{ FLO71-NW-C } & $a(\mathrm{~km} / \mathrm{sec}) \div$ & & & & 6.6 & & 8.15 & Fig. 5(a) & $\mathbf{A}$ \\
\hline & $\mathrm{H}(\mathrm{km})$ & & & & 42.0 & & $(42.0)$ & & \\
\hline NE-C & $\mathrm{H}(\mathrm{km})$ & & & & 43.0 & & $(43.0)$ & Fig. 5(b) & $\mathbf{B}$ \\
\hline SE-C & $\mathbf{H}(\mathrm{km})$ & & & & 44.0 & & $(44.0)$ & Fig. 5(c) & $\bar{C}$ \\
\hline \multirow{4}{*}{$\begin{array}{l}\text { Early Rise (Modified)** } \\
\text { Green and Hales (1968) } \\
\text { FLO71-NW-D }\end{array}$} & $a(\mathrm{~km} / \mathrm{sec})$ & & & 6.3 & & 7.0 & 8.05 & Fig. 5(d) & $\mathrm{D}$ \\
\hline & $\mathrm{H}(\mathrm{km})$ & & & 20.0 & & 30.0 & $(50.0)$ & & \\
\hline & $a(\mathrm{~km} / \mathrm{sec})$ & 5.0 & & 6.3 & & 7.0 & 8.15 & Fig. 5(e) & $\mathbf{A}$ \\
\hline & $\mathrm{H}(\mathrm{km})$ & $1.0 \S$ & & 20.0 & & 20.0 & $(41.0)$ & & \\
\hline NW-DI & $\mathrm{H}(\mathrm{km})$ & $1.0 \S$ & & 33.0 & & 8.0 & $(42.0)$ & Fig. 5(e) & $\mathbf{A}$ \\
\hline NE-D & $\mathrm{H}(\mathrm{km})$ & $1.0 \S$ & & 34.0 & & 8.0 & $(43.0)$ & Fig. 5(e) & A \\
\hline SE-D & $\mathrm{H}(\mathrm{km})$ & 1.08 & & 22.0 & & 30.0 & $(53.0)$ & Fig. 5(e) & AA \\
\hline SE-D1 & $\mathrm{H}(\mathrm{km})$ & $1.0 \S$ & & 37.0 & & 14.0 & $(52.0)$ & Fig. 5(e) & A \\
\hline
\end{tabular}

For explanation of symbols, see footnotes to Tables 4 and 5 . 
TABLE 7

Crustal Models Around Madison (MDS)

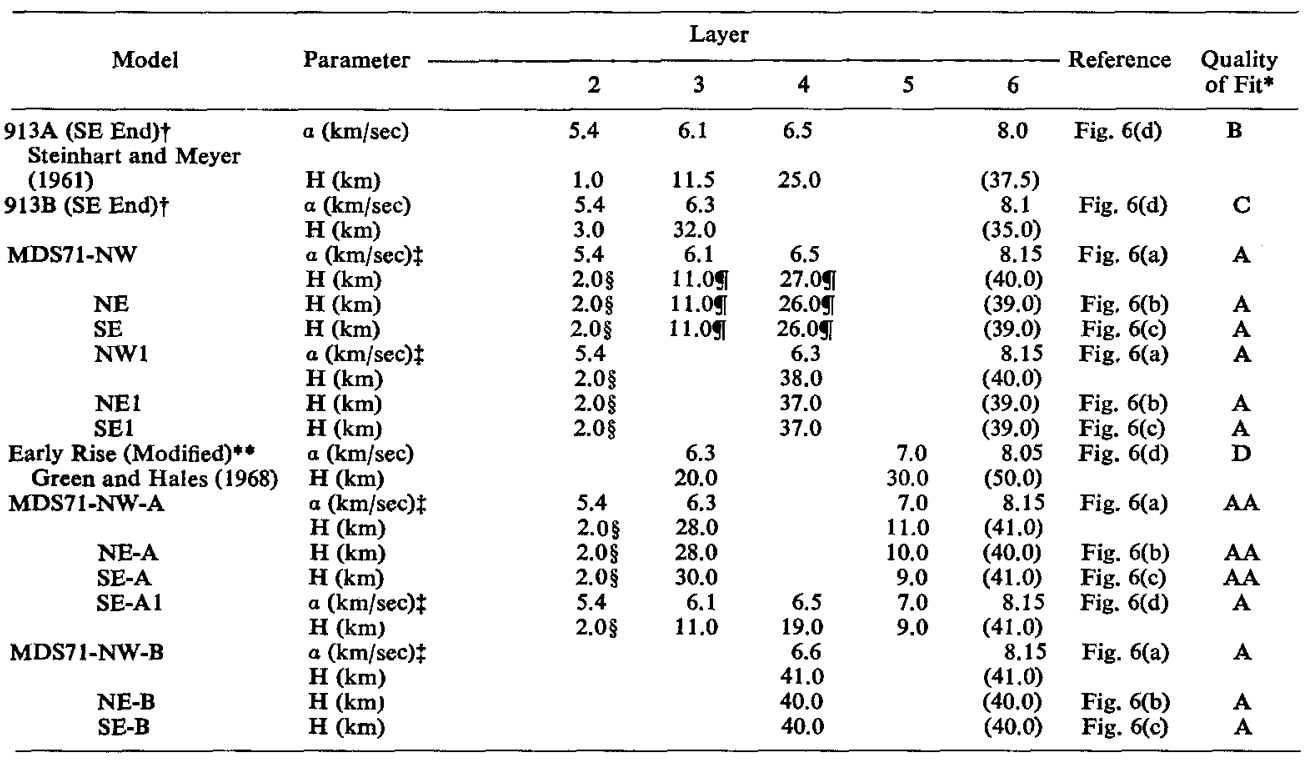

For explanation of symbols, see footnotes to Tables 4 and 5 .

TABLE 8

The Best Crustal Models around SHA, OXF, FLO, AND MDS

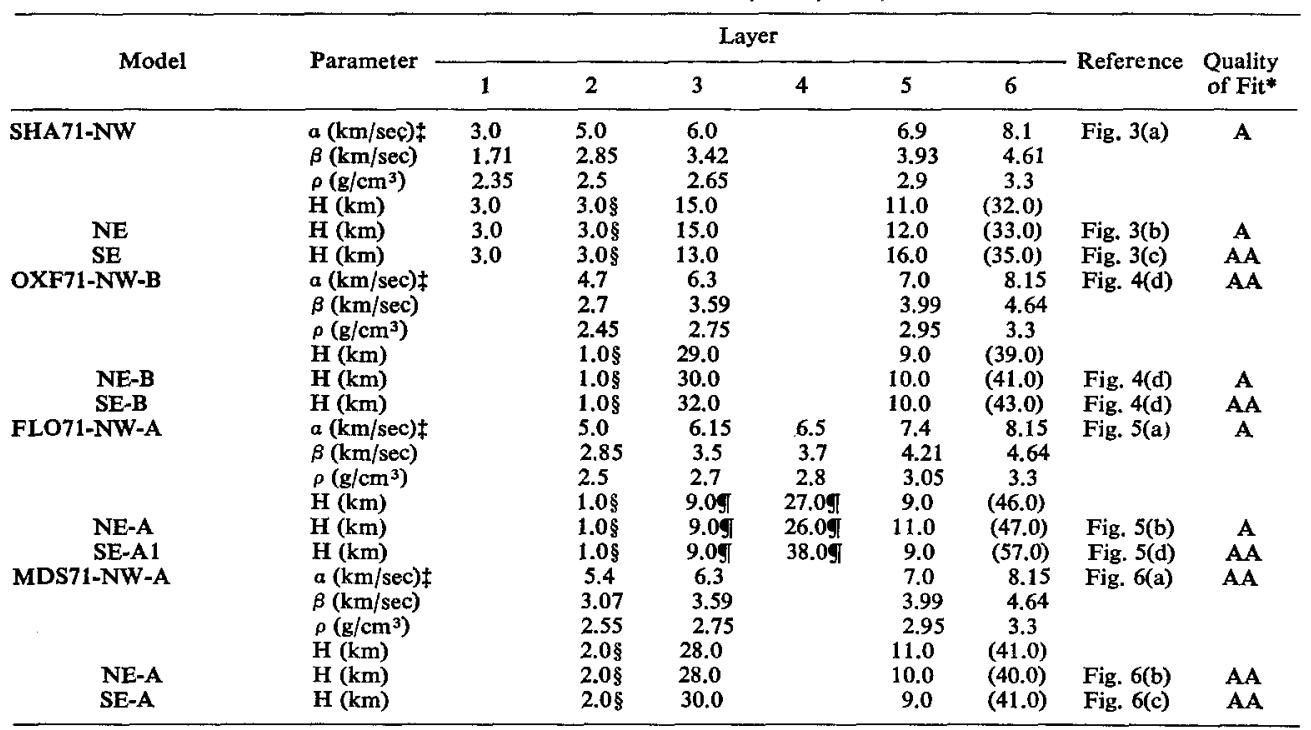

For explanation of symbols, see footnotes to Tables 4 and 5.

\section{Crustal Structure From $P$-Wave Spectra}

Besides the terms, the best-fit model and the best model defined above, we give working definitions for the terms whose meaning is more or less ambiguous. According to James and Steinhart (1966), we define "the crust" as the outer shell of the Earth lying above the level at which the $P$-wave velocity increases rapidly or discontinuously to values in excess of $7.6 \mathrm{~km} / \mathrm{sec}$. When referring the area studied to the geological provinces, such as "the Gulf coastal plain", "the interior plain", and "the superior upland", we refer to Figure 2 of Pakiser and Robinson (1966). 
Spring Hill (SHA). SHA is situated at the southern end of the Gulf coastal plain, facing Mobile Bay. The only refraction profile near SHA runs in a north-south direction about $140 \mathrm{~km}$ west of SHA. Table 4 includes model Ansley, the south end, model Raleigh, the north end of the profile, proposed by Warren, Healy, and Jackson (1966), and model Dribble, the shot point model of the SALMON event of Springer (1966). An assumed $P$-wave velocity model is a composite of these models with the velocity in the uppermost mantle of $8.10 \mathrm{~km} / \mathrm{sec}$ after Herrin (1969). The resultant best-fit models, NW, NE, and SE are shown in Table 4. $\beta$ and/or $\rho$, not shown in the table, are calculated from relations (1) and (2). The transfer ratios of the above models are compared with the observational ratios in Figure 3. The small figures included are referred to alphabetically from top to bottom. The thin curves with shock numbers in Figures 3(a), (b), and (c) show observational transfer ratios. The dotted parts of the curves correspond to the frequency ranges where the signal-to-noise ratio is lower than one-half, or where sufficient reliability of the transfer ratio cannot be expected due to the effects of later phases or reflections around the source. The similarities in the features of the curves, especially the spacing of three peaks within each group and among three groups, imply that the crustal structure around this station may be primarily approximated by horizontal parallel layering. Generally, the lowest-frequency peak (the first peak) is less reliable than the peaknext to it (the second peak). This is experimentally substantiated by the fact that the first peak is usually lower in amplitude and that its position is generally more sensitive to various factors such as differences in data window and time length of analysis. Therefore, the matching of the second peak is considered to be the most important. A satisfactory fit is attained in three sectors. Some discrepancies of the observational ratios among three sectors have resulted in some differences in each layer and total crustal thicknesses.

Next, based on a unilayered velocity model shown in Table 4, models, NW-A, NE-A, and SE-A are obtained. These models almost attain the matching of the peak positions, but discrepancies in the relative height of the peaks are noticeable. These discrepancies, however, can largely be reconciled by an introduction of a low-velocity surface layer. This is apparent from a comparison of the transfer ratio of model SE-Al with the $3.0-\mathrm{km} /$ sec surface layer of 4-km thickness in Figure 3(d), with the observational ratios in Figure 3(c). A comparison of the transfer ratios of models, SE, SE1, SE2, and SE3 in Figures 3 (c) and (d), shows that variations in thickness of the $3.0-\mathrm{km} / \mathrm{sec}$ layer have a noticeable effect on the transfer ratios as compared with the negligible effect of the $5.0-\mathrm{km} / \mathrm{sec}$ layer, and that the thickness of the $3.0-\mathrm{km} / \mathrm{sec}$ layer can be unambiguously determined, especially from the phase difference.

Oxford $(O X F)$. OXF is located about $100 \mathrm{~km}$ east of the Mississippi River near an intersection of the Gulf coastal plain and the interior plain. The Arkansas profile runs northeast from Little Rock about $250 \mathrm{~km}$ west of OXF. The models at Little Rock, the southwest end, and at Cape Girardeau, the northeast end of the profile, as proposed by McCamy and Meyer (1966) are shown in Table 5. An assumed $P$-wave velocity model is mainly based on the above velocity model. The observational ratios at this station, shown in Figure 4, show a narrower spacing of four peaks, as compared with a wider spacing of three peaks for those at SHA. This may imply an underlying thicker crust. The consistency of the observational ratios within each group and among three groups, may suggest that the layering is approximately horizontal and parallel. The resultant models are composed of three groups of models in which the $7.4-\mathrm{km} / \mathrm{sec}$ layer is either thick, thin, or missing. The thickness of the $4.7-\mathrm{km} / \mathrm{sec}$ layer is arbitrarily assumed as $1 \mathrm{~km}$, because we have no certain information on it. An increase in thickness of this layer to several kilometers serves only to heighten the fourth peak. For the SE group which contain reliable observational ratios of deep earthquakes, model SE1 is preferred to models SE and SE2 


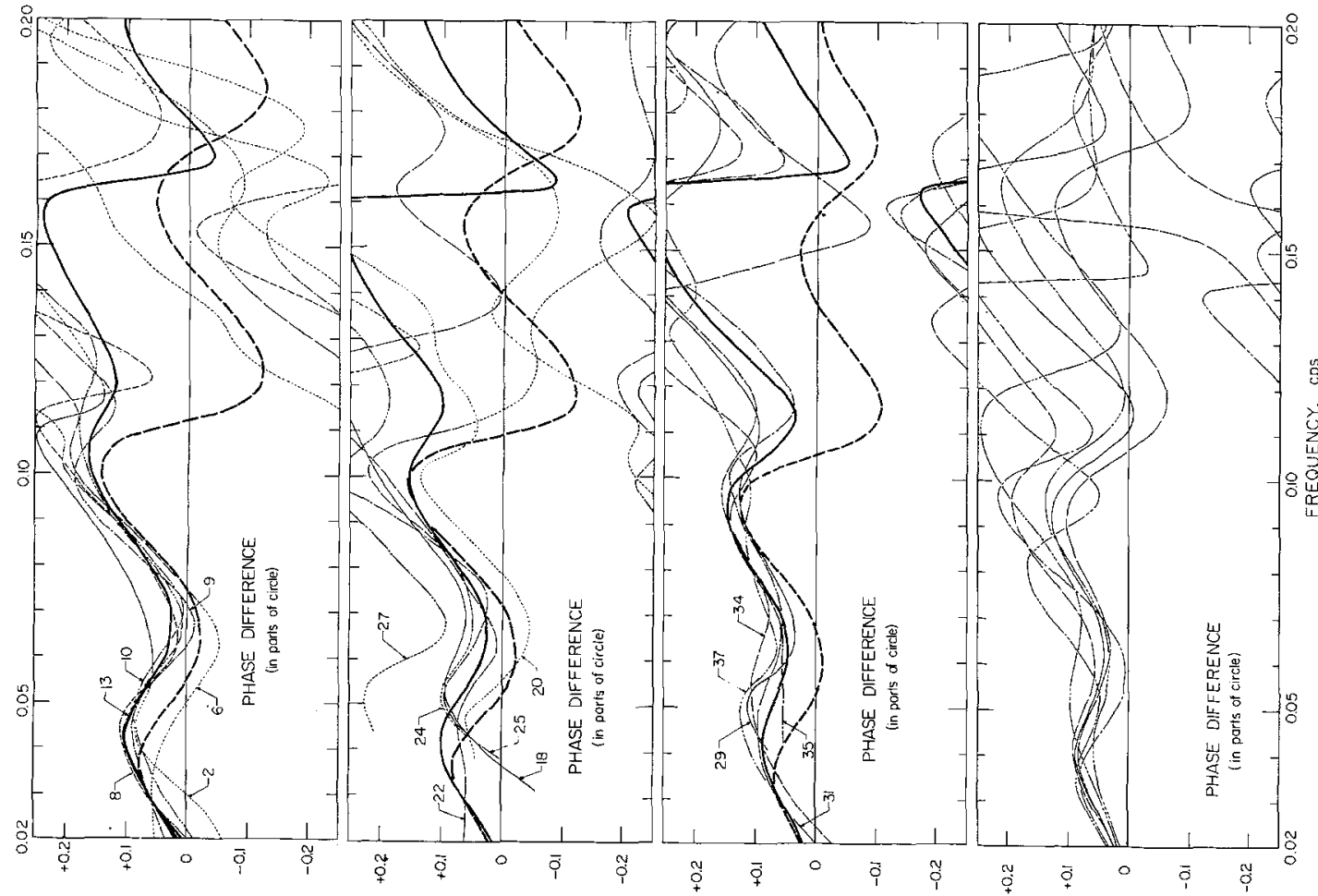

0
0
0
0

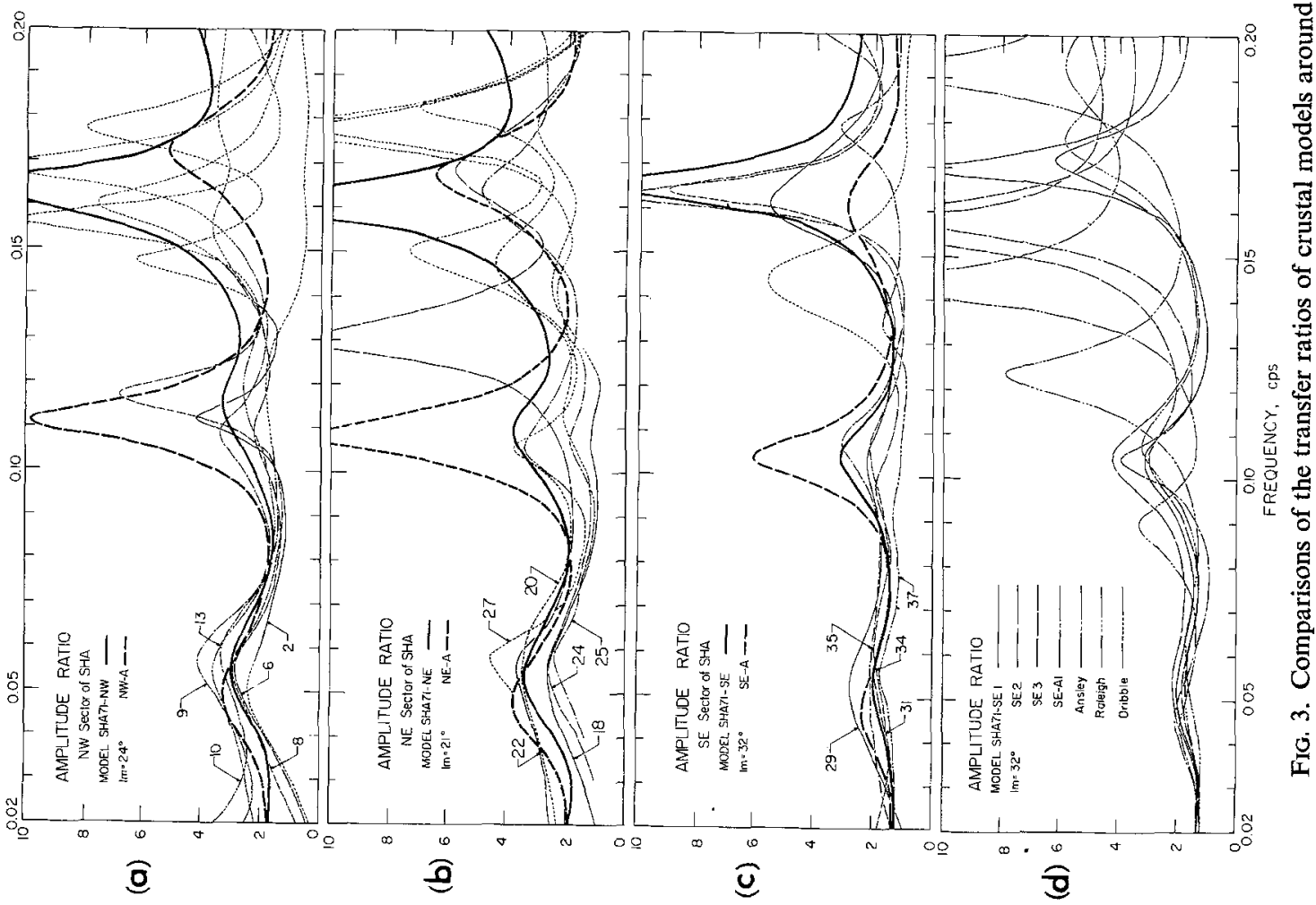




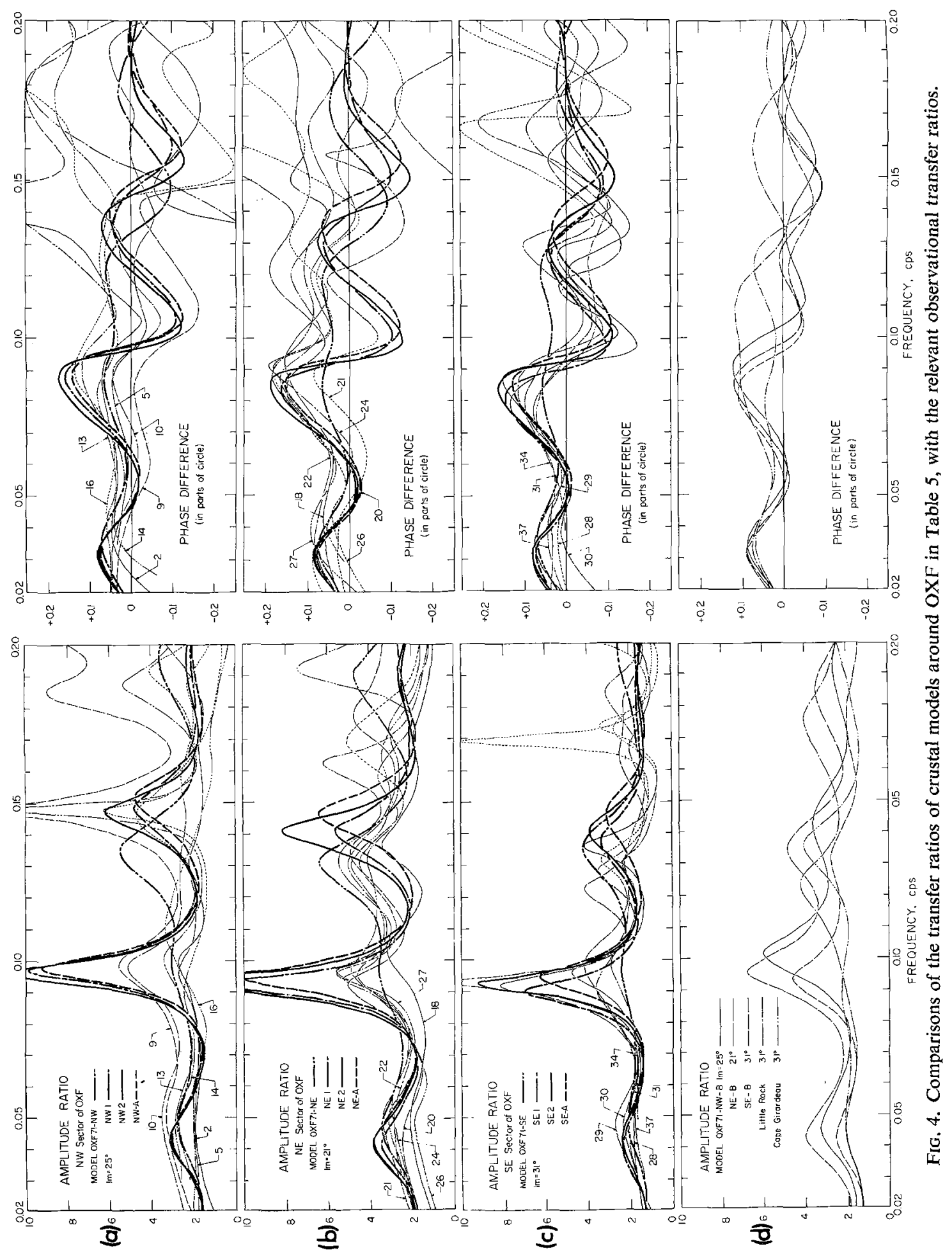


because of the better fitting of the relative heights of the peaks. But for the other two groups, this is not the case. Table 5 contains also the best unilayered models in each sector.

The Little Rock profile of Project Early Rise passes about $200 \mathrm{~km}$ west of OXF. Green and Hales (1966) made a travel-time study for the Little Rock and Wichita profiles and proposed a model shown in Table 5. A comparison of the transfer ratio of this model in Figure 6(d) with the observational ratios in Figure 4(c) shows that the crustal thickness, as much as $50 \mathrm{~km}$, is too thick to attain a satisfactory fit. An assumed $P$-wave velocity model is based mainly on the above proposed model. The transfer ratios of the inferred models, NW-B, NE-B, and SE-B shown in Figure 4(d), succeed in raising the fourth peak and depressing the second peak and thereby attain a much better fit than those of the other models.

Florrisant (FLO). FLO is situated in the midst of the interior plain, and the area surrounding this station has been an object of extensive studies of crustal structure, as apparent from Table 1 of McEvilly (1964). However, the structures estimated by various investigators are not consistent. This may imply the complex structure there. Indeed, although most of the records analyzed are of the earthquakes common to most of the stations, only the observational ratios at FLO, especially the amplitude ratios, show a marked inconsistency in each group and among three groups, as is apparent from Figure 5. Peaks of the observational ratios in the SE group are generally lower than those for the other groups and for the other stations. In addition, the second peak splits into two closely spaced peaks when the window length, $T_{2}$ is increased from 30 to $40 \mathrm{sec}$. Although this splitting is not observed for the other two groups, we regard two closely spaced peaks as more reliable, because $30 \mathrm{sec}$ cannot include the latter part of the reverberations in the crustal layering and its resolution is intrinsically lower.

From a detailed study of two reversed refraction surveys made in Missouri, Stewart (1968) concluded that the crust in northern Missouri may be characterized by three major layers of $6.1,6.2$, and $6.6 \mathrm{~km} / \mathrm{sec}$ with an underlying upper mantle of $8.0 \mathrm{~km} / \mathrm{sec}$, but that the crust in southern Missouri is so laterally inhomogeneous that it cannot be approximated by any simply layered structure. The northern Missouri profile passes in a westerly direction from Hannibal at about $130 \mathrm{~km}$ northwest of FLO, while the southern Missouri profile runs toward the southwest from Ste. Genevieve at about $100 \mathrm{~km}$ southeast of FLO. For the NE and NW sectors, we assume a velocity model composed primarily of the northern Missouri model of Stewart (1968), except for the velocity in the uppermost mantle of $8.15 \mathrm{~km} / \mathrm{sec}$ according to Herrin (1969). For the $\mathrm{SE}$ sector, assumed velocity models are composed mainly of two models, one with and one without a $6.9-\mathrm{km} /$ sec layer, proposed by Stewart (1968) for southern Missouri. The proposed models for the end of both profiles near FLO and the resultant models are shown in Table 6. The transfer ratios of these models are compared with the observational ratios in Figure 5. Only in the NW sector is a satisfactory fit attained.

We next assume a velocity model composed mainly of the model proposed by McCamy and Meyer (1966) for the Arkansas profile. Cape Girardeau, the northeast end of this profile is situated about $180 \mathrm{~km}$ southeast of FLO. The inferred models attain a satisfactory fit for all three sectors. For the SE sector, two models, SE-A and SE-A1 are obtained, depending on whether the splitting of the second peak is taken into account or not. Although the latter model is preferred, as presented in the above discussion, the crustal thickness of this model is slightly too thick for the adopted time length. However, since a slightly longer time length does not bring about a substantial change in observational ratios, we may regard this model as nearly correct, and will settle this problem in Kurita (1973b). Models, NW-A, NE-A, and SE-A1 are preferred to models, NW, NE, and SE. Based on a composite of the above two assumed velocity models, we have obtained models, NW-B, NE-B, and SE-B, which give excellent or satisfactory fit. A 
(a)

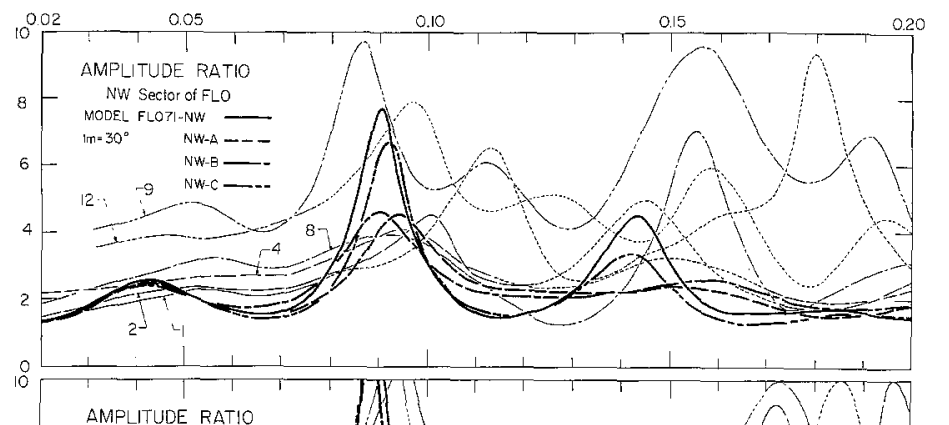

(b)

(c)

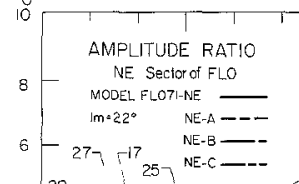

(d)

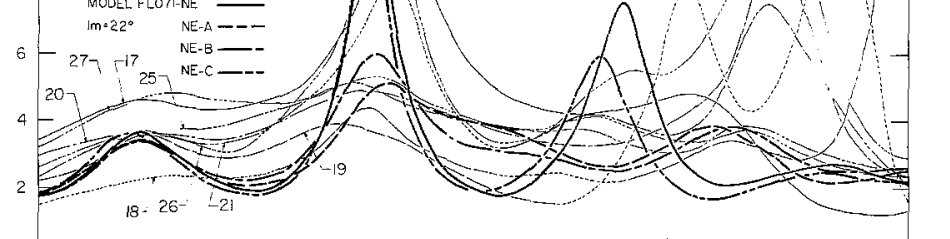

(e)
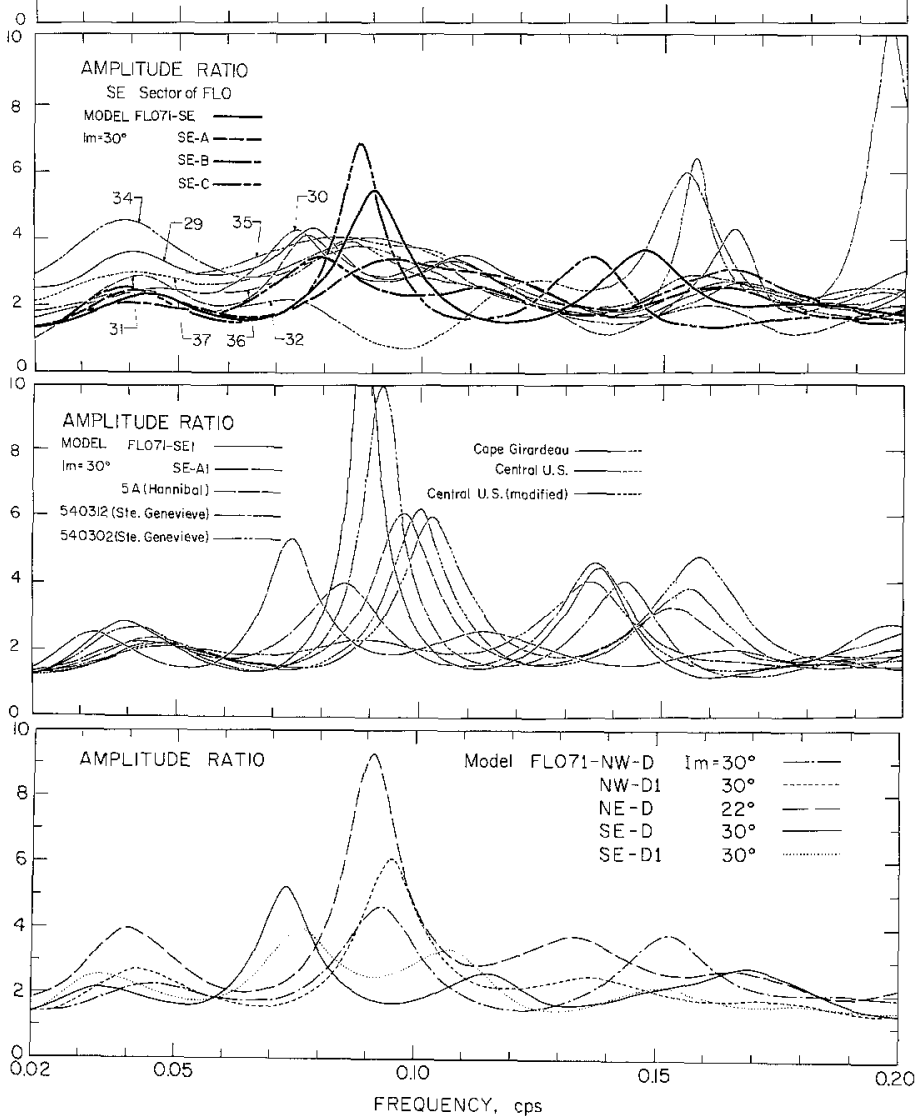

FIG. 5.1.

FIG. 5. Comparisons of the transfer ratios of crustal models around FLO in Table 6, with the relevant observational transfer ratios. 
(a)

(b)

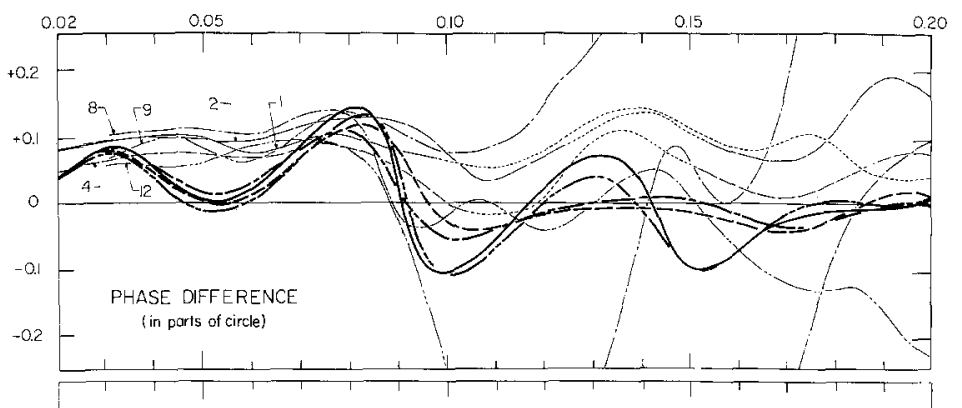

(c)

(d)

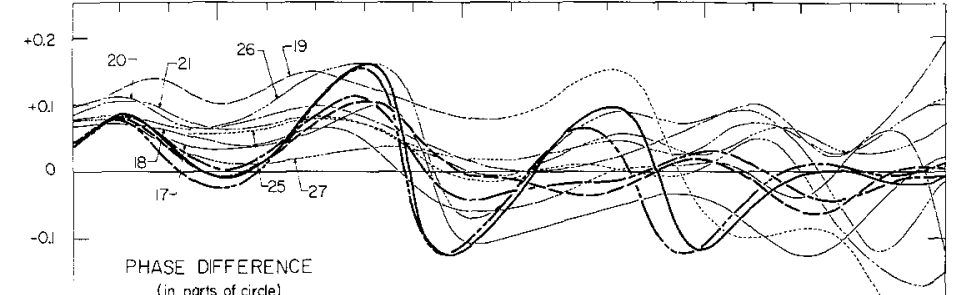

c)

$$
-0.2-\quad \text { (in parts of circle) }
$$

(e)
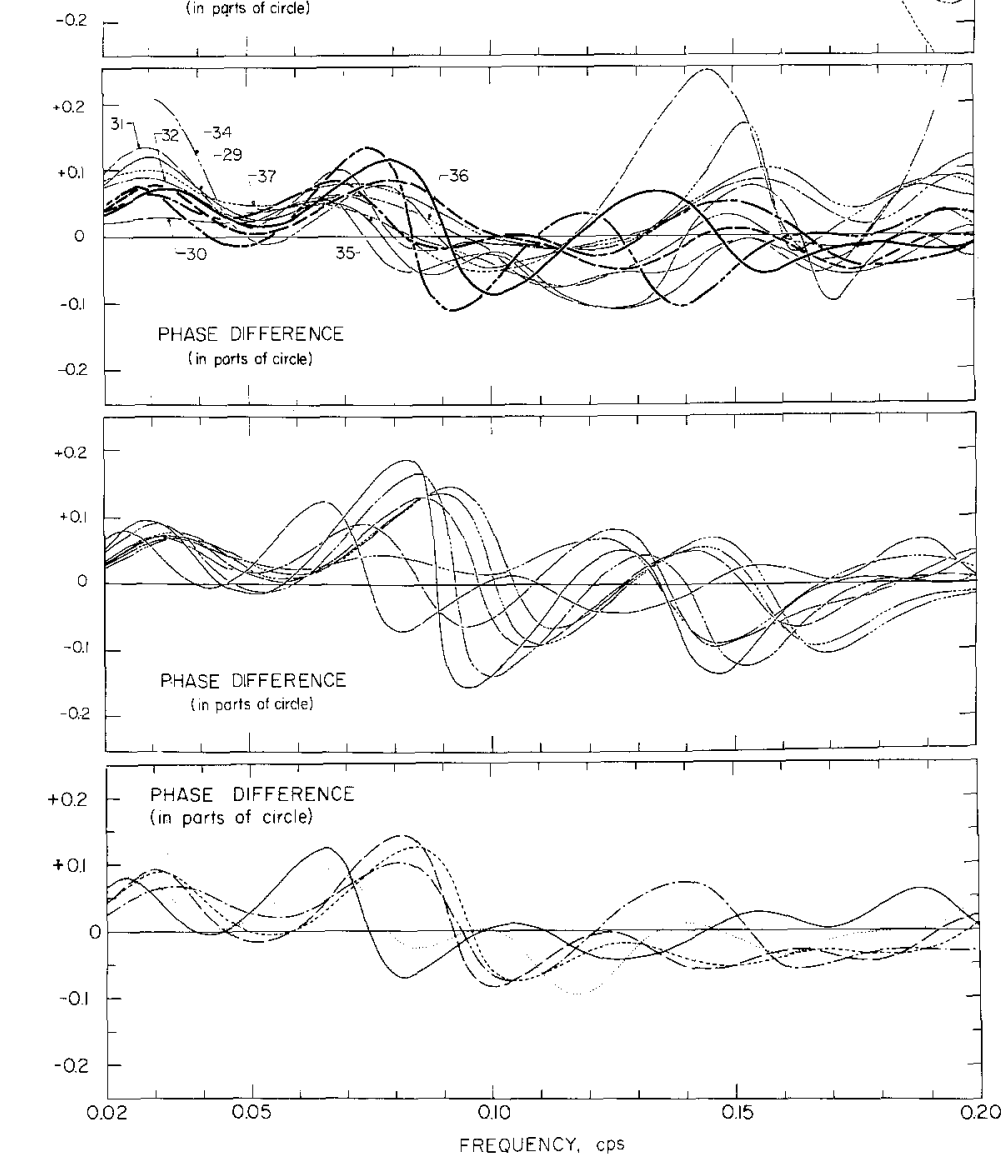

FIG. 5.2. 

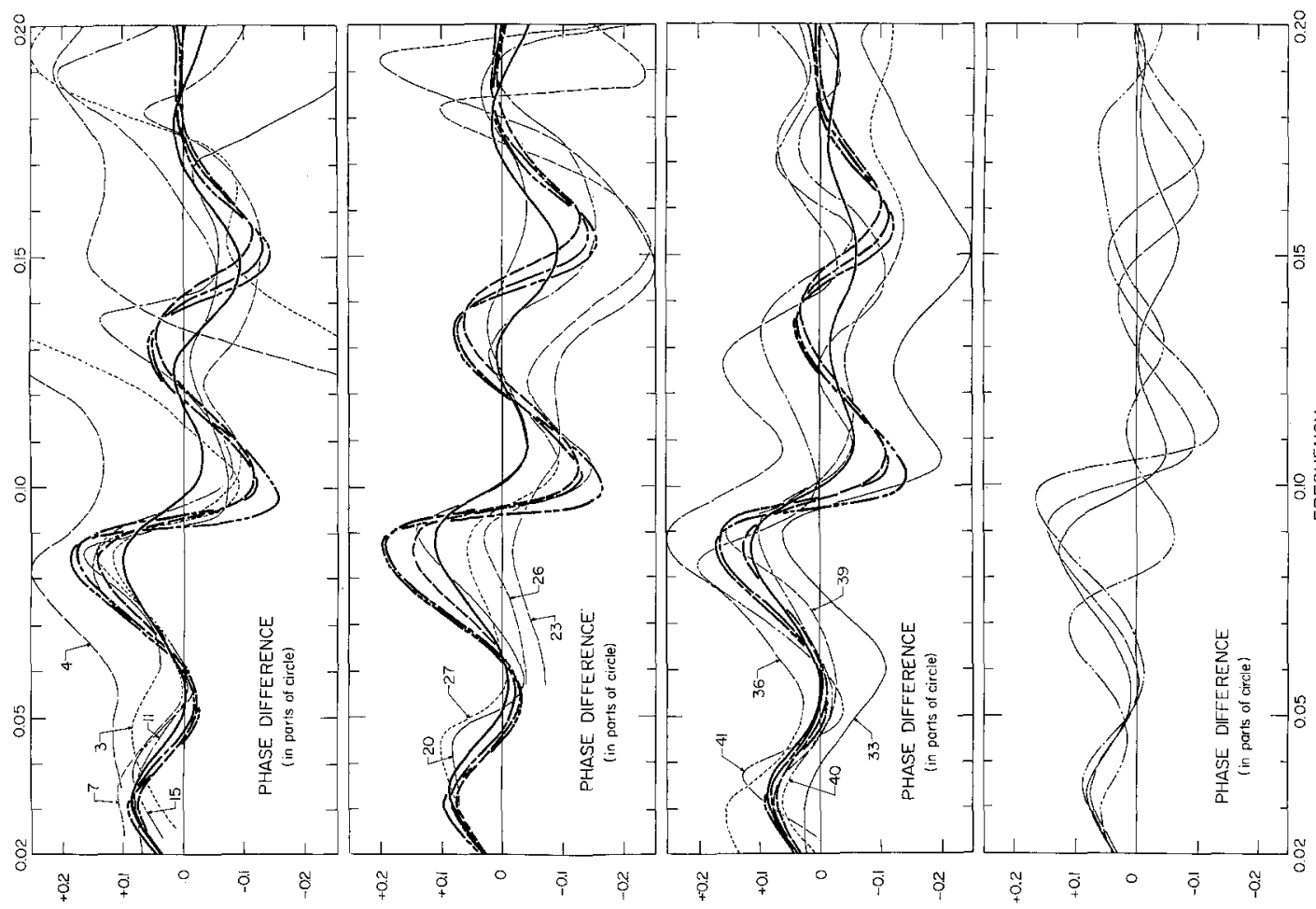

.

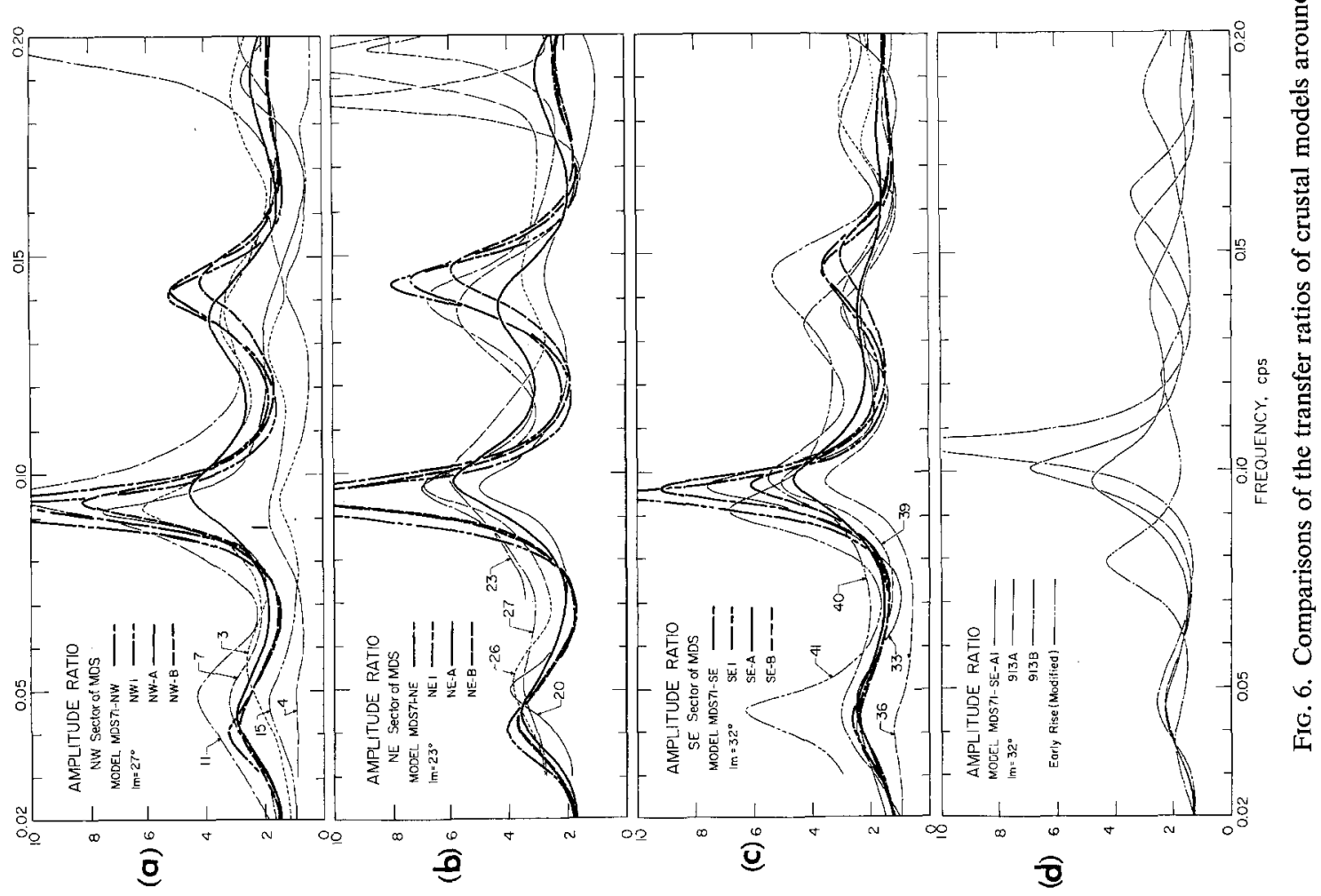


discrimination of these models from models, NW-A, NE-A, and SE-A1 is impossible. At present, we prefer the latter models to avoid any artificiality.

Table 6 contains the central U.S. model of McEvilly (1964) obtained from a study of phase-velocity dispersion. This model does not attain a satisfactory fit mainly due to its thinner crustal thickness of $38 \mathrm{~km}$. In the modified central U.S. model, S-wave velocities and densities calculated with relations (1) and (2) are adopted. The difference in transfer ratio of both models is slight, as apparent from Figure 5(d). This table also includes the one- and two-layer models proposed by Fernandez and Careage (1968) for the crust around FLO, from a study of $P$-wave amplitude spectra of a deep earthquake, and the best unilayered models for each sector.

Finally, we assume a velocity model based mainly on the Early Rise model of Green and Hales (1968). The Little Rock profile passes about $50 \mathrm{~km}$ west of FLO. The transfer ratios of these models shown in Figure $5(\mathrm{e})$, fit well with the observational ratios in Figures 5(a), (b), and (c). Taking into account the consistency of layer configuration for three sectors, we can divide these models into two groups, NW-D1, NE-D, and SE-D1,
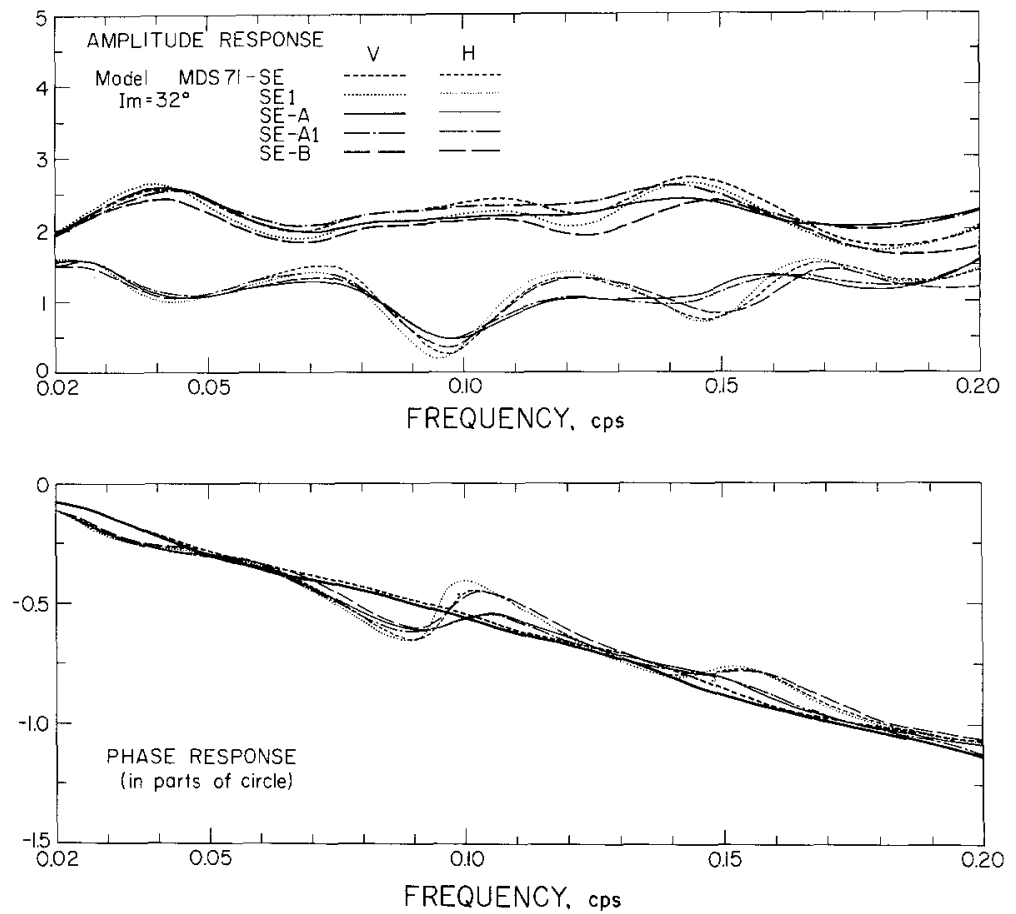

FIG. 7. Comparisons of the vertical (V) and horizontal $(\mathbf{H})$ components of the transfer functions (amplitude and phase responses) of $P$ wave of unit amplitude incident at the bottom of the crustal models obtained for the SE sector of MDS. The wave is incident with an angle of $32^{\circ}$ and a zero phase shift. For the vertical component of phase response, the response curves are shown for only two models, SE and SE-A, because models, SEl and SE-B, and model SE-Al show nearly the same feature as model SE, and model SE-A, respectively.

and NW-D and SE-D. We may be able to find a model with a fair fit for the NE sector of the latter group, but we prefer the former group, although further evidence is needed to substantiate this selection. We may prefer models, NW-A, NE-A, and SE-A1 to models, NW-D1, NE-D, and SE-D1 because of the excellent fit of model SE-A1 as compared with a satisfactory fit for model SE-D1, although again further evidence is desirable.

Madison (MDS). MDS is located near an intersection of the interior plain and the superior upland. It is about $340 \mathrm{~km}$ south of Lake Superior, where detailed refraction studies such as Smith, Steinhart, and Aldrich (1966), elucidated the complex crustal 
structure. Since this station was closed during December, 1966, a sufficient amount of data cannot be expected, and most of the records analyzed are of shallow earthquakes. Nevertheless, the observational ratios are quite consistent in each group and among three groups, and show nearly the same features as those for OXF.

According to a compilation of McConnell, Gupta, and Wilson (1966), the refraction profile 913 shown in Figure 8 as the Wisconsin profile which extends from about $90 \mathrm{~km}$ northeast of MDS nearly to the northwest, is the only reversed survey near MDS. Assumed velocity models are based mainly on two models, 913A and 913B, proposed by Steinhart and Meyer (1961) for the SE end of this profile. The proposed and inferred models are shown in Table 7, and their transfer ratios are compared with the observational ones in Figure 6. Models, NW, NE, and SE and models, NW1, NE1, and SE1 based on the two velocity models give equally satisfactory fit.

Next, we assume a $P$-wave velocity model based on the Early Rise model of Green and Hales (1966). The Little Rock profile passes only about $20 \mathrm{~km}$ west of MDS. The transfer ratios of inferred models, NW-A, NE-A, and SE-A succeed in raising the fourth peak and depressing the second peak, which results in a better fit than the transfer ratios of models, NW1, NE1, and SE1, without the $7.0-\mathrm{km} / \mathrm{sec}$ layer. The transfer ratio of model SE-A1 in Figure 6(d) shows that division of the $6.3-\mathrm{km} / \mathrm{sec}$ layer into the $6.1-$ and $6.5-\mathrm{km} / \mathrm{sec}$ layers produces almost the same, just a slightly worse, fit.

The best unilayered models, NW-B, NE-B, and SE-B, also can give satisfactory fit and have crusts only $1 \mathrm{~km}$ thicker than models, NW1, NE1, and SE1. Taking into account the crustal velocity difference of $0.3 \mathrm{~km} / \mathrm{sec}$ between both groups of models and a negligible effect of the 5.4-km/sec layer on the transfer ratio, this fact shows difficulty in estimating the velocity structure by this method within the frequency range concerned. Eventually, models, NW-A, NE-A, and SE-A are selected as the best models. However, the other models with satisfactory fit in Table 7 , may possibly be substituted for the best models. This is apparent from Figure 7, which compares the amplitude and phase responses of all resultant models for the SE sector. Except for some discrepancies for frequencies higher than $0.10 \mathrm{~Hz}$ between models, SE-A and SE-A1, and the other models, the response spectra show almost the same features. In this situation, by assuming either of the above models, we may approximately eliminate the crustal effect from observed spectra, at least for the vertical motion.

\section{Discussion}

Three sectors around each station, as shown in Figure 8, may be considered as the approximate regions with which the inferred crustal models are concerned. The width of each sector is mostly based on the direction of wave approach from earthquakes shown in Figure 1, while the stretch from the station to the end of the sector is taken as two parts in three of the approximate horizontal distance between the station and the position of the $P$ coda which is incident at the station $40 \mathrm{sec}$ later than the direct $P$ waves after reverberations in the lower crustal layer of the best models shown in Table 8 . As for FLO, we may possibly replace the tabulated models by models derived from the Early Rise velocity model in Table 6. For the NW sector of FLO, model FLO71-NW also cannot be ruled out. Table 9 shows the estimated crustal thickness for the best models and the best unilayered models whose velocities are assumed common to all stations. The crustal thickness of both groups differs at most 10 per cent, but shows almost the same regional variations. It also appears that a thicker crust is concerned with a higher average velocity in the crust. If we take possible alternative models for FLO, the crustal thickness of the NW and NE sectors reduces to about $42 \mathrm{~km}$. In any case, the general trend of the depth 


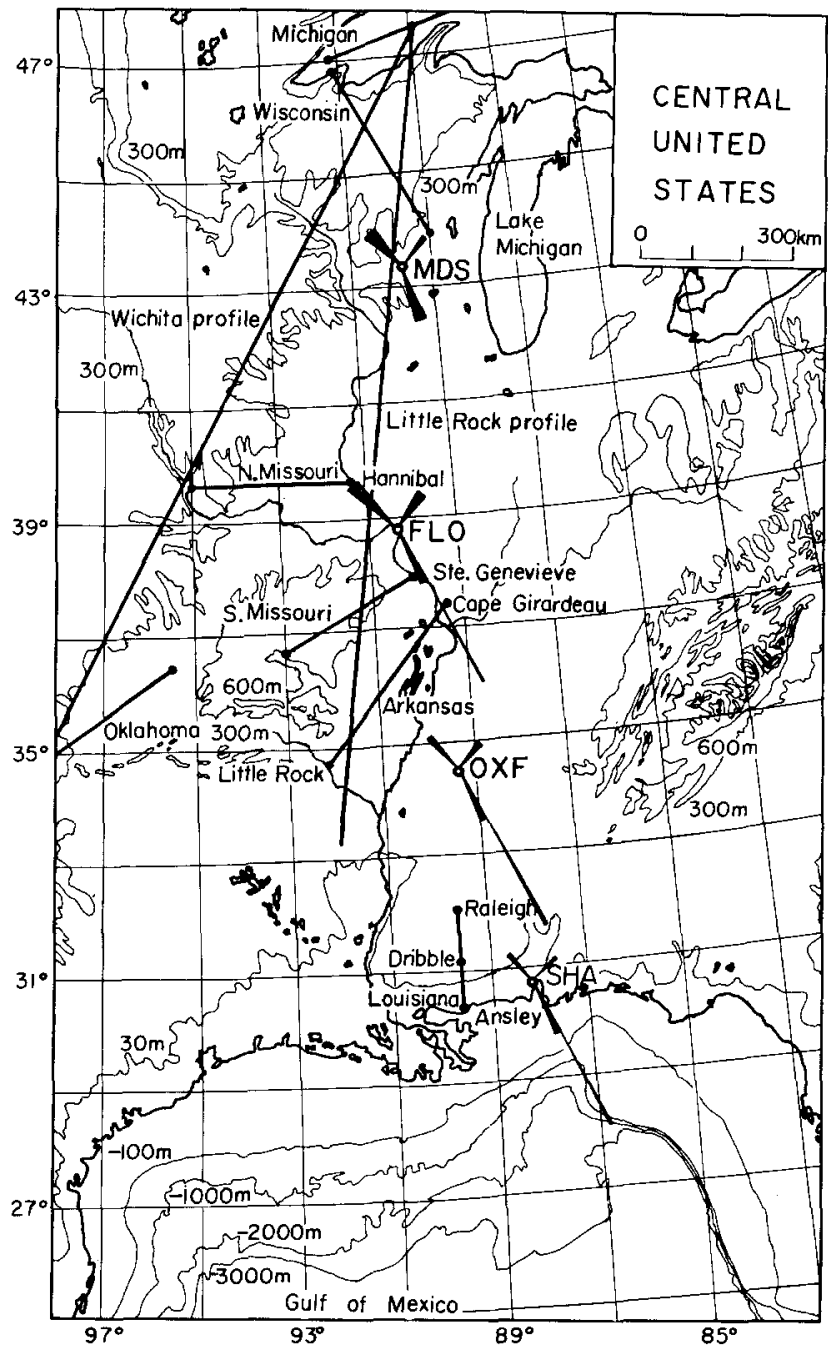

FIG. 8. Map of the central United States. Three sectors enclosing each station nearly correspond to the areas where the crustal structure has been investigated. A long sector extending from the station nearly to the southeast is concerned with the upper mantle structure studied in Kurita (1973b). Solid lines show profiles of major refraction surveys made in this region.

TABLE 9

Estimated Crustal Thicknesses in Kilometers for the Best Models Shown in Table 8, and Unilayered Models Whose P-Wave Velocities in the Crust and Upper Mantle ARE 6.60 AND $8.15 \mathrm{KM} / \mathrm{SEC}$, RESPECTIVELY

\begin{tabular}{ccccccccccc}
\hline & \multicolumn{3}{c}{ Best Model (Stations) } & & \multicolumn{3}{c}{ Unilayered Model (Stations) } \\
\cline { 2 - 4 } \cline { 7 - 10 } & SHA & OXF & FLO & MDS & & SHA & OXF & FLO & MDS \\
\hline NW & 32 & 39 & 46 & 41 & & 34 & 39 & 42 & 41 \\
NE & 33 & 41 & 47 & 40 & & 35 & 40 & 43 & 40 \\
SE & 35 & 43 & $57^{*}$ & 41 & & 37 & 41 & 44 & 40 \\
Average & 33 & 41 & 47 & 41 & & 35 & 40 & 43 & 40 \\
\hline
\end{tabular}

* Value omitted in averaging.

of the Moho may match well with the topographic feature from the Gulf of Mexico to Lake Superior.

Progressive crustal thickening of a few kilometers from the NW, NE, to SE sectors, except for the crust around MDS, is observed in both groups of the models in Table 9. To our regret, however, we are not certain of this result. Since we have utilized the records of shallow earthquakes to examine regional variations in crustal structure around the station, 
there is a possibility that a consistent bias of the records of the earthquakes among three sectors has resulted in a systematic shift of peak positions of observational ratios and, accordingly, a systematic discrepancy in crustal thickness. In relation to this fact, the probable error of the total crustal thickness may be no more than a few kilometers for an assumed velocity structure. For the probable error of each layer thickness, we may assign almost the same thickness except for the assumed thickness of the 4.7- to 5.4-km/ sec layer and a pair of the layers for which the mutual transfer of their thicknesses is possible by as much as $10 \mathrm{~km}$ (see Tables 5,6 , and 7).

An interesting feature concerning the resultant velocity structure is that among assumed $P$-wave velocity models, the Early Rise model has brought about the best models for OXF and MDS, and possibly for FLO, although a marked discrepancy in crustal thickness as much as $10 \mathrm{~km}$ is observed between the proposed model and most of the inferred models. This may be mainly due to the fact that their model represents an average feature over the whole region covered by two profiles. We note that the crustal thickness of $50 \mathrm{~km}$ of their model nearly coincides with $51 \mathrm{~km}$ estimated by Tryggvason and Qualls (1967) and is not far from $46.5 \mathrm{~km}$ obtained by Mitchell and Landisman (1971), for the crust in Oklahoma. Since the Early Rise model is not concerned with the southern part of the profiles, the horizontal extrapolation of this velocity model to the structure around OXF may be inappropriate. However, the observational ratios at OXF show almost the same feature as those at MDS where the Early Rise velocity model is well applied, and the transfer ratios of the best models at OXF fit pretty well with the observational ratios there. Accordingly, these models may be regarded as nearly appropriate to the structure around OXF. For the other stations, the horizontal extrapolation is within $200 \mathrm{~km}$. This amount of extrapolation may be permissible, unless there are some unfavorable situations.

The most impressing fact concerning the best models is that they are composed of layers with common features. Except for an additional $3.0-\mathrm{km} / \mathrm{sec}$ layer at SHA, this is apparent from an inspection of the parameters in the same row of Table 8. Especially the best models at OXF and MDS show similar features. An apparent inconsistency of the observational ratios at FLO has resulted in a marked discrepancy in layer configuration of the models between the NW and NE sectors and the SE sector. We are certain of the complicated structure around FLO, but not certain whether or not the difference in structure between two groups of the sectors is just the same as shown in Table 8 . We require further data, especially some good records of deep earthquakes in the KurileJapan region to settle this problem. Figure 12 of Christensen (1965) depicts a relation between rock composition and $P$-wave velocity. The velocity in the upper crust from 6.1 to $6.5 \mathrm{~km} / \mathrm{sec}$ is appropriate for silicic rock, ranging in composition from granite to diorite, with an average composition close to granodiorite or their metamorphic equivalents, whereas the velocity in the lower crust from 6.9 to $7.0 \mathrm{~km} / \mathrm{sec}$ is appropriate for mafic rock with a composition close to gabbro or its metamorphic equivalent. Some inclusion of altered ultramafic rocks may be expected for a probable 7.4-km/sec layer around FLO. The velocity in the uppermost mantle of 8.10 to $8.15 \mathrm{~km} / \mathrm{sec}$ is suitable for ultramafic rock with a composition of predominant peridotite. Pakiser and Robinson (1966), based on results of previous refraction surveys, concluded that the crustal thickness in the United States is predominantly controlled by the thickness of mafic rock in the lower crust. Although the scope of the region in discussion is different, our results indicate the reverse situation that variations in crustal thickness are primarily dominated by silicic upper crust. This is consistent with a finding of Mitchell and Landisman (1971) from a study of refraction surveys in Oklahoma and eastern New Mexico, that the upper 15 to $20 \mathrm{~km}$ of the crustal layers controls the difference in crustal thickness. Further discussions on rock composition and related problems are difficult without further data. 
Departures from a plane-layered configuration and anelastic or anisotropic properties of the crust, may have some effects on the transfer ratio. However, a conventional amount of anelasticity in the crust has only a negligible effect (Kurita, 1970), whereas anisotropy, if it exists, may be small (Kurita, 1973d), and, accordingly, its effect may be neglected. As for the structural complexity, we limit our discussion to dipping and transitional layer boundaries. Transitional boundary generally lowers the height of peaks of the transfer ratio (Kurita, 1969). A dipping layer interface has the same effect for waves propagating in the down-dip direction, while the situation reverses for waves in the up-dip direction (Ishii and Ellis, 1970). However, an inclination of layer interface within about $10^{\circ}$ has a negligible effect for the lower frequencies concerned. A problem somewhat related to the inclination of the layer interface is a possible deviation of the real direction of wave approach from the geometrical azimuth. The effect of this deviation is also small (Kurita, 1973b).
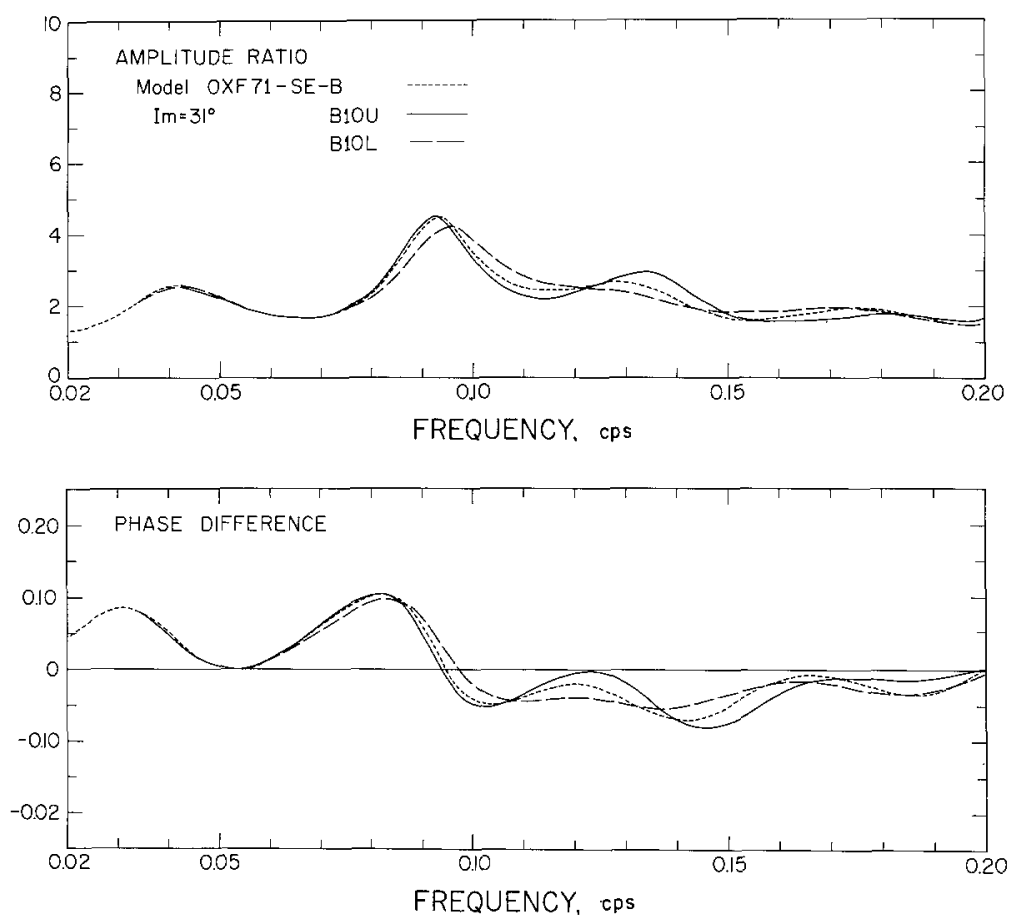

FIG. 9. Comparison of the transfer ratio of model OXF71-SE-B, with those of models, SE-B10U and SE-B10L in which the upper and lower boundaries of the mafic layer of model OXF71-SE-B are replaced by a transitional layer of $10-\mathrm{km}$ thickness, respectively.

Our method is not sensitive enough to detect a small velocity gradient such as about $0.010 \mathrm{~km} \mathrm{sec}^{-1} \mathrm{~km}^{-1}$ in the silicic layer in and around the interior plain obtained by Green and Hales (1968) from a travel-time study of Project Early Rise, and $0.005 \mathrm{~km}$ $\mathrm{sec}^{-1} \mathrm{~km}^{-1}$ in the silicic layer around FLO suggested by Hill (1971) from a study on amplitude decay of head waves. The following discussion is concerned with the possible existence of more prominent gradual velocity variations with depth, which are sometimes possible as an interpretation of data of refraction surveys, as discussed by McCamy and Meyer (1966). As an interpretation of the layered structure of the inferfed models, the thin layer interleaved such as the 5th layer of models, OXF71-NW1, NE1, and SE1 in Table 5, or two adjacent layers for which the velocity difference is small such as the second and third layers of models, FLO71-NW, NE, SE, and SE1 in Table 6, may be regarded as 
implications of the transitional nature of the layer interface. Examination of the extent to which the transitional layering is likely at layer interfaces, is possible only for the SE sector of SHA, OXF, and FLO, where the height of peaks of observational ratios of deep earthquakes is rather reliable. As apparent from Figures 3, 4, and 5, the transfer ratios of the inferred models, especially of the best models in Table 8 , give almost the same general feature as their corresponding observational ratios, including the height of peaks. Although the model composed of constant-velocity layers is almost certainly an oversimplification, the above fact implies that the inferred models can be a satisfactory approximation to the actual structure. Figure 9 compares the transfer ratio for model OXF71-SE-B with those of models SE-B10U and SE-B10L in which the upper and lower boundaries of the $7.0-\mathrm{km} / \mathrm{sec}$ layer of model OXF71-SE-B are replaced by a transitional layer $10 \mathrm{~km}$ thick, respectively. In the actual computation, each $5-\mathrm{km}$ interval above and below the boundary is divided into sublayers with $0.2-\mathrm{km}$ thickness. This may give a good
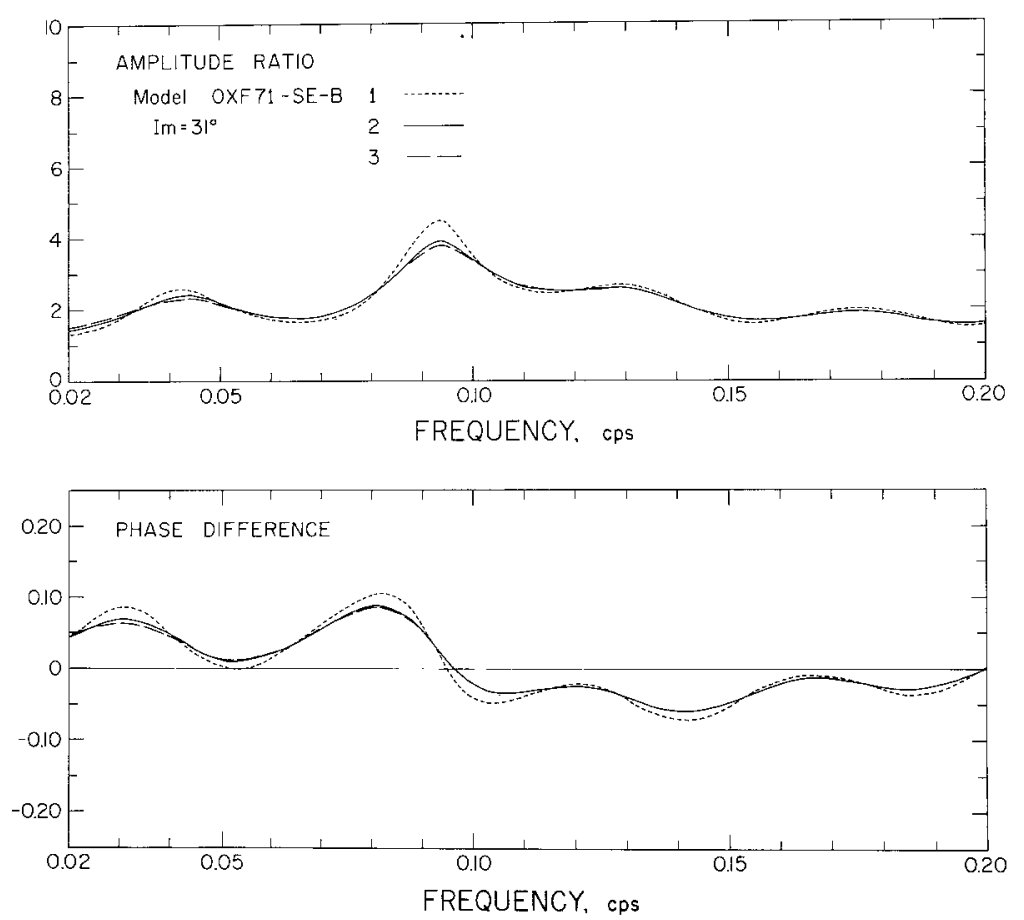

FIG. 10. Comparison of the nontruncated and truncated transfer ratios of model OXF71-SE-B: (1) $L_{w}(\omega) / L_{u}(\omega) ;(2) L_{w}(\omega)^{*} W_{1}(\omega) / L_{u}(\omega)^{*} W_{1}(\omega) ;(3) B(\omega) L_{w}(\omega) I(\omega)^{*} W_{1}(\omega) / B(\omega) L_{u}(\omega) I(\omega)^{*} W_{1}(\omega)$.

approximation to a smooth transitional layering. It appears from the figure that the lower boundary (Moho) consisting of a transitional layer of over 10-km thickness greatly suppresses the peaks at the higher frequencies, whereas a gradient for the upper boundary causes no decreases and sometimes even heightens peaks at the higher frequencies. Although not shown, a transitional layering of over $15-\mathrm{km}$ thickness at the upper boundary and of over $20 \mathrm{~km}$ between the $6.3 \mathrm{-km} / \mathrm{sec}$ layer and the Moho smooth out the fourth peak, while the transitional layer of over $5-\mathrm{km}$ thickness at each or both boundaries does not bring about a substantial change in the height of peaks. From comparisons of observational ratios in Figure 4(c) with the transfer ratios above, and similar comparisons for the other best models, we may conclude that transitional layering thicker than about $5 \mathrm{~km}$ is unlikely for the Moho, but a gradient up to about $10-\mathrm{km}$ thickness is 
possible for the discontinuities in the lower crust. The above discussion is based on the replacement of a sharp discontinuity by a transitional layer in the inferred models. Therefore, a possibility remains that a quite different model with transitional layers will attain a better fit, but its possibility may be very low.

$S$-wave velocities have been assumed through an assumed Poisson's ratio of 0.26 for the crust and uppermost mantle. A decrease in Poisson's ratio generally lowers peaks and shifts them to higher frequencies, and an increase in Poisson's ratio causes a reverse effect. Poisson's ratio of about 0.25 to 0.26 may be appropriate to the crust and uppermost mantle for the region studied. A decrease in Poisson's ratio to 0.25 has little effect on the transfer ratio, and causes at most $1-\mathrm{km}$ thinner crust. Possible variations in densities from values inferred from the relation (2) have a negligible effect.

Figure 10 compares the transfer ratio, $L_{w}(\omega) / L_{u}(\omega)$ which has been used above, with truncated transfer ratio, $L_{w}(\omega) * W_{1}(\omega) / L_{u}(\omega) * W_{1}(\omega)$ and $B(\omega) L_{w}(\omega) I(\omega) * W_{1}(\omega) /$ $B(\omega) L_{u}(\omega) I(\omega) * W_{1}(\omega)$ which was formulated in Kurita (1973a), for model OXF71-SE-B. $L_{w}(\omega)$ and $L_{u}(\omega)$ show the vertical and horizontal motions of the transfer function, respectively. $W_{1}(\omega)$ is the spectral window corresponding to the data window, $w_{1}(t)$ having a time length of $80 \mathrm{sec}$ which was used dominantly in the above analysis. $B(\omega)$ and $I(\omega)$ are the spectrum of the wave incident at the Moho (Kurita, 1973c), and the instrumental response, respectively. In computing $I(\omega)$, the critical damping is assumed from an examination of the calibration pulses. From this comparison and others not shown, it appears that the combined effect of the spectrum of the incident wave and the instrumental response is small, whereas the effect of truncation is rather marked. However, in the light of the present reliability of the observational ratio, it seems unnecessary to disqualify the models obtained above by the nontruncated transfer ratio method. More detailed studies of the crustal structure, based on the truncated transfer ratio, require more reliable observational ratio. They can possibly be obtained from analysis of highquality records of deep earthquakes. It may be noteworthy to observe from a comparison of Figures 9 and 10 that the existence of the transitional layering in the crust dominantly changes the height of peaks at frequencies higher than about $0.10 \mathrm{~Hz}$, while the effect of truncation mainly affects the height of peaks at frequencies lower than about $0.10 \mathrm{~Hz}$.

\section{CONCLUSIONS}

The crustal structure in the central United States has been studied by the transfer ratio method from an analysis of teleseismic, long-period $P$ waves recorded at SHA, OXF, FLO, and MDS. Since the inferred models are composed of homogeneous, isotropic, horizontal parallel layers and contain some assumed layer parameters, the actual structures around the stations are certainly different from the inferred models. As for the longperiod waves with periods longer than about $5 \mathrm{sec}$, however, the dynamic response of these models can be almost equivalent to that of the actual structures.

The general features of the crustal structure in this region are summarized as follows:

(a) The crust is primarily approximated by a stack of horizontal parallel layers within about $100-\mathrm{km}$ areas around SHA, OXF, and MDS. The crustal structure around FLO is rather complicated.

(b) The crust is about $33 \mathrm{~km}$ thick near the coast of the Gulf of Mexico (SHA), and thickens to about $41 \mathrm{~km}$ near an intersection of the Gulf coastal plain and the interior plain (OXF). It further thickens to about $47 \mathrm{~km}$ or more in the midst of the interior plain (FLO), and thins to about $41 \mathrm{~km}$ toward an intersection of the interior plain and the superior upland (MDS). As for the crust around FLO, however, its thickness reduces to about $42 \mathrm{~km}$, if the $P$-wave velocity in the lower crust is taken as $7.0 \mathrm{~km} / \mathrm{sec}$ instead of $7.4 \mathrm{~km} / \mathrm{sec}$. 
(c) A sedimentary layer having a velocity of about $3.0 \mathrm{~km} / \mathrm{sec}$ is confined to the Gulf coastal plain. This layer is about $3 \mathrm{~km}$ thick near the coast of the Gulf of Mexico, and tapers out to the north.

(d) A near-surface layer with a velocity of about 4.7 to $5.4 \mathrm{~km} / \mathrm{sec}$ and having a thickness of about 1 to $3 \mathrm{~km}$ is a prevailing feature.

(e) In each of the regions referred to in (b), the thickness of the silicic upper crust with a velocity of about 6.0 to $6.5 \mathrm{~km} / \mathrm{sec}$ is about $15,30,35$, and $30 \mathrm{~km}$, respectively.

(f) The mafic lower crust with a velocity of about 6.9 to $7.0 \mathrm{~km} / \mathrm{sec}$ and having a thickness of about $10 \mathrm{~km}$, is a common feature possibly except for the midst of the interior plain around FLO, where a velocity of about $7.4 \mathrm{~km} / \mathrm{sec}$ is probable, implying an inclusion of ultramafic rocks.

(g) The uppermost mantle velocity of about $8.10 \mathrm{~km} / \mathrm{sec}$ near the coast of the Gulf of Mexico increases to about $8.15 \mathrm{~km} / \mathrm{sec}$ to the north.

(h) Deeper interfaces in the crust may possibly be replaced by the transitional layering up to $10 \mathrm{~km}$ thick.

(i) The crustal thickness is predominantly controlled by the silicic upper crust.

\section{ACKNOWLEDGMENTS}

The author is grateful to Don L. Anderson and Brian J. Mitchell for their critical reviews of this manuscript. He is also indebted to Vard A. Nelson for assistance in selecting data, and Otto W. Nuttli for information on angle of incidence. This research was supported by the Advanced Research Projects Agency and was monitored by the Air Force Office of Scientific Research under Contracts F44620-69-C0067 and F44620-72-C-0078.

\section{REFERENCES}

Banghar, A. R. (1970). New tables of angles of incidence of $P$ waves as a function of epicentral distance, Earthquake Notes 61, 45-58.

Christensen, N. I. (1965). Compressional wave velocities in metamorphic rocks at pressures to 10 kilobars, J. Geophys. Res. 70, 6147-6164.

Fernandez, L. M. and J. Careaga (1968). The thickness of the crust in central United States and La Paz, Bolivia, from the spectrum of longitudinal seismic waves, Bull. Seism. Soc. Am. 58, 711-741.

Green, R. W. E. and A. L. Hales (1968). The travel times of $P$ waves to $30^{\circ}$ in the central United States and upper mantle structure, Bull. Seism. Soc. Am. 58, 267-289.

Herrin, E. (1969). Regional variations of $P$-wave velocity in the upper mantle beneath North America, Am. Geophys. Union, Geophys. Mon. Ser. 13, 242-246.

Herrin, E., et al. (1968). 1968 seismological tables for $P$ phases, Bull. Seism. Soc. Am. 58, 1193-1241.

Hill, D. P. (1971). Velocity gradients and anelasticity from crustal body wave amplitudes, J. Geophys. Res. 76, 3309-3325.

Ishii, H. and R. M. Ellis (1970). Multiple reflection of plane $P$ and $S V$ waves by a dipping layer, Geophys. $J$. 20, 11-30.

James, D. E. and J. S. Steinhart (1966). Structure beneath continents: A critical review of explosion studies 1960-1965, Am. Geophys. Union, Geophys. Mon. Ser. 10, 293-333.

Jeffreys, H. and M. Shimshoni (1964). The times of $p P, s S, s P$, and $p S$, Geophys. J. 8, 324-337.

Kurita, T. (1969). Crustal and upper mantle structure in Japan from amplitude and phase spectra of longperiod $P$-waves, Part 1. Central mountain area, J. Phys. Earth 17, 13-41.

Kurita, T. (1970). Crustal and upper mantle structure in Japan from amplitude and phase spectra of longperiod $P$-waves, Part 3. Chugoku region, J. Phys. Earth 18, 53-78.

Kurita, T. (1973a). A procedure for elucidating fine structure of the crust and upper mantle from seismological data, Bull. Seism. Soc. Am. 63, 189-209.

Kurita, T. (1973b). Upper mantle structure in the central United States from $P$ and $S$ wave spectra, $P h y s$. Earth Planet. Int. 6.

Kurita, T. (1973c). Source time functions of some deep earthquakes occurred in South America. (in preparation). 
Kurita, T. (1973d). Crustal and upper mantle structure in the central United States from surface-wave dispersion, travel-time residuals, and synthetic seismograms. (in preparation).

McCamy, K. and R. P. Meyer (1966). Crustal results of fixed multiple shots in the Mississippi embayment, Am. Geophys. Union, Geophys. Mon. Ser. 10, 370-381.

McConnell, R. K. Jr., R. N. Gupta, and J. T. Wilson (1966). Compilation of deep crustal seismic refraction profiles, Rev. Geophys. 4, 41-100.

McEvilly, T. V. (1964). Central U.S. crust-upper mantle structure from Love and Rayleigh wave phase velocity inversion, Bull. Seism. Soc. Am. 54, 1997-2015.

Mitchell, B. J. and M. Landisman (1971). Geophysical measurements in the Southern Great Plains, Am. Geophys. Union, Geophys. Mon. Ser. 14, 77-93.

Nafe, J. E. and C. L. Drake (1963). Physical properties of marine sediments, in The Sea, 3, 794-815, John Wiley \& Sons, New York.

Pakiser, L. C. and R. Robinson (1966). Composition of the continental crust as estimated from seismic observations, Am. Geophys. Union, Geophys. Mon. Ser. 10, 620-626.

Phinney, R. A. (1964). Structure of the earth's crust from spectral behavior of long-period body waves, J. Geophys. Res. 69, 2997-3017.

Smith, T. J., J. S. Steinhart, and L. T. Aldrich (1966). Lake Superior crustal structure, J. Geophys. Res. $71,1141-1172$.

Springer, D. L. (1966). Calculation of first-zone $P$-wave amplitudes for SALMON event and for decoupled sources, J. Geophys. Res. 71, 3459-3467.

Steinhart, J. S. and R. P. Meyer (1961). Explosion studies of continental structure, Carnegie Inst. Wash. Publ. 622, 409 pp.

Stewart, S. W. (1968). Crustal structure in Missouri by seismic-refraction methods, Bull. Seism. Soc. Am. 58, 291-323.

Tryggvason, E. and B. R. Qualls (1967). Seismic Refraction measurements of crustal structure in Oklahoma, J. Geophys. Res. 72, 3738-3740.

Warren, D. H., J. H. Healy, and W. H. Jackson (1966). Crustal seismic measurements in southern Mississippi, J. Geophys. Res. 71, 3437-3458.

Woollard, G. P. (1959). Crustal structure from gravity and seismic measurements, J. Geophys. Res. 64, 1521-1544.

\section{Seismological Laboratory}

California Institute of Technology

Pasadena, California 91109

Contribution 2179 of the Division of

Geological and Planetary Sciences

Manuscript received February 26, 1973 